\title{
Proteomic analysis of estrogen response of premalignant human breast cells using a 2-D liquid separation/mass mapping technique
}

\author{
Jia Zhao ${ }^{1}$, Kan Zhu ${ }^{1}$, David M. Lubman ${ }^{1,2,3}$, Fred R. Miller ${ }^{4,5}$, Malthy P. V. Shekhar, ${ }^{4,}$ \\ Brigitte Gerard ${ }^{4}$ and Timothy J. Barder \\ ${ }^{1}$ Department of Chemistry, University of Michigan, Ann Arbor, MI, USA \\ ${ }^{2}$ Department of Surgery, University of Michigan Medical Center, Ann Arbor, MI, USA \\ ${ }^{3}$ Comprehensive Cancer Center, University of Michigan Medical Center, Ann Arbor, MI, USA \\ ${ }^{4}$ Breast Cancer Program, Barbara Ann Karmanos Cancer Institute, Detroit, MI, USA \\ ${ }^{5}$ Department of Pathology, Wayne State University School of Medicine, Detroit, MI, USA \\ ${ }^{6}$ Eprogen, Darien, IL, USA
}

\begin{abstract}
A 2-D liquid-phase separation method based on chromatofocusing and nonporous silica RP-HPLC followed by ESI-TOF-MS was used to analyze proteins in whole cell lysates from estrogen-treated and untreated premalignant, estrogen-responsive cell line MCF10AT1 cells. 2-D mass maps in the $\mathrm{pH}$ range 4.6-6.0 were generated with good correlation to theoretical $M_{\mathrm{r}}$ values for intact proteins. Proteins were identified based on intact $M_{\mathrm{p}} \mathrm{pI}$ and PMF, or MS/MS sequencing. About 300 unique proteins were identified and 120 proteins in mass range $5-75 \mathrm{kDa}$ were quantified upon treatment of estrogen. Around 40 proteins were found to be more highly expressed ( $>$ four-fold) and 17 were down-regulated ( $>$ four-fold) in treated cells. In our study, we found that many altered proteins have characteristics consistent with the development of a malignant phenotype. Some of them have a role in the ras pathway or play an important role in signal pathways. These changed proteins might be essential in the estrogen regulation mechanism. Our study highlights the use of the MCF10AT1 cell line to examine estrogen-induced changes in premalignant breast cells and the ability of the 2-D mass mapping technique to quantitatively study protein expression changes on a proteomic scale.
\end{abstract}

Received: March 31, 2005
Revised: January 29, 2006
Accepted: February 7, 2006

\section{Keywords:}

Biomarker / Breast cancer / Liquid chromatography / Mass spectrometry

\section{Introduction}

Breast carcinoma is the second leading cause of cancerrelated death in women in the Western world [1]. Despite significant improvements in cancer diagnosis and treatment,

Correspondence: Dr. David M. Lubman, Department of Surgery, The University of Michigan Medical Center, MSRB1, 1150 West Medical Center Drive, Ann Arbor, MI 48109-0656, USA

E-mail: dmlubman@umich.edu

Fax: +1-734-615-8108

Abbreviations: CF, chromatofocusing; E2, estradiol; ER, estrogen receptors; NPS, nonporous silica; $\boldsymbol{n}$-OG, $n$-octyl- $\beta$-D-glucopyranoside
40000 women are expected to die from the disease this year [2]. The effect of ovarian hormones such as estrogen on breast cancer risk was first shown over 100 years ago when researchers found that removing the ovaries of women with breast cancer improved their chances of survival. Furthermore, lifetime exposure to estrogen is associated with increasing a woman's risk for breast cancer [3, 4].

The growth of breast cancer cells is under the control of estrogenic hormones and growth factors [5]. Estrogen is a hormone that is essential for the normal growth and development of the breast and tissues important for sexual reproduction. Estrogen is produced by the ovaries and aromataseexpressing cells peripheral to the ovaries. It is recognized and used in estrogen target tissues with estrogen recep- 
tors (ER) such as the breast and uterus. The ER enters the nucleus and turns on the estrogen-responsive genes, which stimulate cell division. The progression from a normal cell to a cancer cell is a multi-step process that includes the build-up of damage to the DNA in key genes that control cell division and proliferation. Because estrogen stimulates cell division, it can enhance a spontaneous or chemically induced mutation. It can also indirectly stimulate cell division in the breast by affecting the level of other hormone receptors or growth factors [6].

To follow changes in cancer cells at the molecular level, the most commonly used method is to monitor the activation of different genes via mRNA expression as the cancer evolves. In order to gain accurate quantitation of gene expression levels in cells or tissues, DNA microarray techniques have been developed. The drawback of these techniques is that the correlation between mRNA and protein levels has been insufficient to predict protein expression levels from quantitative mRNA data [7]. In addition, genomic analysis provides the predicted sequence of proteins rather than the functional form found in the cell. A cell is normally dependent upon a multitude of metabolic and regulatory pathways for its survival. Proteomics is complementary to genomics because it focuses on the gene products, which are the active agents in cells. In addition, the number of protein isoforms expressed by a cell can be ten-fold higher than the number of coding genes where various protein modifications exist. Global protein profiling becomes the approach to address the complexity and changes in expression, including PTMs, during tumorigenesis. Proteomic analysis has been used widely in finding candidate biomarkers for early detection of cancer $[8,9]$.

Estrogen-induced changes are typically examined using human breast cancer MCF-7 cells. The MCF-7 line has been useful to study estrogen response and to develop selective ER modifiers such as tamoxifen [10] for breast cancer treatment. Because it expresses the ER, MCF-7 is often regarded as an early stage cancer and a model for examining altered estrogen response during progression. However, MCF-7 cells were derived from a malignant pleural effusion, which developed after treatment of two previous recurrences that occurred over a 3-year period. MCF-7 cells are aneuploid, nearly tetraploid, with a mean chromosomal number of 85 [11] and a DNA index of 1.7 [12]. Thus, MCF-7 is a poor model to test for alterations in early development of cancer from premalignant lesions. We have used the premalignant, estrogen-responsive cell line MCF10AT1 to examine the estrogen-induced changes in the proteome.

In order to study the estrogen-induced proteome, a novel CF-nonporous silica (NPS)-RP-HPLC-online-ESITOF-MS mass mapping approach is applied to analyze proteins from the premalignant human breast cell line before (MCF10AT1) and after treatment with estradiol (E2) (MCF10AT1E2) [13, 14]. In this study, the protein identification is based on PMF, MS/MS analysis, accurate MW, and $\mathrm{p} I$ of intact proteins. This method includes the fractionation of proteins based on $\mathrm{pI}$ in the first dimension using chromatofocusing (CF) and protein hydrophobicity in the second dimension using RP-HPLC which is followed by online ESI-TOF-MS detection. As a result, a 2-D mass map with $\mathrm{p} I$ in the first dimension and MW in the second dimension can be created. The abundance of proteins can be estimated by the peak area of the intact protein. The advantage of the method is that accurate $\mathrm{pI}$ and MW can be obtained for each protein. Moreover, since MS is a very specific detector, it can differentiate and quantify proteins that coelute. As a result, more proteins can be quantified with greater specificity compared to the 2-D UV map.

In this study, the protein identification is based on PMF, MS/MS analysis, accurate MW and pI of intact proteins. Proteins are identified by PMF using MALDI-TOF-MS or peptide sequencing using MALDI-TOF-TOF. The intact protein MW is obtained by ESI-TOF-MS in which $M_{\mathrm{r}}$ accurate to $<150 \mathrm{ppm}$ can be achieved. This method is essential for identifying the "exact" form of protein including information such as PTM, truncations, and isoforms of key proteins. The human breast epithelial cell line used in this study is premalignant in xenografts $[15,16]$. The advantage of cell lines is the availability of a stable phenotype that can be modified after transfection with genes of interest. Since the MCF10AT1 can develop into xenograft lesions in different stages of cancer, it can truly mimic the progression of cancer. In this work, about 300 unique proteins are identified in the $\mathrm{pH}$ range studied (4.6-6.0) and around 120 high-abundance proteins are accurately quantified in the mass range $5-75 \mathrm{kDa}$. The 2-D mass maps and the corresponding protein identifications are valuable for proteomic analysis of cellular protein expression changes associated with E2 treatment. These proteins potentially play a role in the development of breast cancer.

\section{Materials and methods}

\subsection{Cell culture}

MCF10AT1 cells were grown in monolayer on plastic in DMEM/F12 medium (1:1 mixture of DMEM and Ham's F-12 medium) supplemented with $5 \%$ horse serum, $10 \mu \mathrm{g} /$ $\mathrm{mL}$ of insulin, $20 \mathrm{ng} / \mathrm{mL}$ epidermal growth factor, and $0.5 \mu \mathrm{g} / \mathrm{mL}$ of hydrocortisone. MCF10AT1E2 lysates were prepared by treating $\sim 50 \%$ confluent MCF10AT1 cell monolayers with $10^{-9} \mathrm{M}$ E2 for $24 \mathrm{~h}$. The cells were then collected by scraping and washed twice with PBS buffer before being stored at $-70^{\circ} \mathrm{C}$.

\subsection{Cell lysis and buffer exchange}

Approximately 70-80 million cells were thawed and lysed with five volumes of lysis buffer which consists of 7.5 M urea, 2.5 M thiourea, 4\% n-octyl- $\beta$-D-glucopyranoside (n-OG), $10 \mathrm{mM}$ tris(2-carboxyethyl)phosphine (TCEP), $12.5 \% \mathrm{v} / \mathrm{v}$ glycerol, and $1 \% \mathrm{v} / \mathrm{v}$ protease inhibitor cocktail 
(Sigma, St. Louis, MO, USA). The mixture was vortexed frequently over a period of $1 \mathrm{~h}$ at room temperature and then centrifuged at $15000 \times \mathrm{g}$ for $40 \mathrm{~min}$ at $4^{\circ} \mathrm{C}$. After the supernatant was collected, buffer exchange was conducted against the CF start buffer using a PD-10 G-25 column (Amersham Biosciences, Piscataway, NJ, USA). The buffer-exchanged protein mixtures were stored in a $-80^{\circ} \mathrm{C}$ freezer until further use. The Bradford assay [17] was used to quantify the amount of protein in mixtures.

\section{$2.3 \mathrm{CF}$}

CF separation was performed on an HPCF-1D column (250 mm $\times 2.1 \mathrm{~mm}$ ) (Beckman Coulter, Fullerton, CA, USA) using an ultra-plus II MD pump (Micro-tech Scientific, Vista, CA). Prior to sample loading, the column was equilibrated with a start buffer containing $25 \mathrm{mM}$ bis-tris propane (Sigma), $6 \mathrm{M}$ urea, and 1\% $n$-OG. The $\mathrm{pH}$ of the start buffer was adjusted to $\mathrm{pH} 7.4$ with saturated iminodiacetic acid solution. After equilibration, $4.5 \mathrm{mg}$ of proteins were loaded onto the CF column. Elution is achieved by applying a $\mathrm{pH} 4.0$ elution buffer that consists of $10 \% \mathrm{v} / \mathrm{v}$ Polybuffer 74 (Amersham Pharmacia, Piscataway, NJ), $6 \mathrm{M}$ urea, and $1 \% \mathrm{n}$-OG at a flow rate of $0.2 \mathrm{~mL} / \mathrm{min}$. A linear $\mathrm{pH}$ gradient is generated at the outlet of the column. As a result, proteins elute off the column sequentially according to their $\mathrm{p} I$. Separation is monitored at $280 \mathrm{~nm}$ using a UV detector. Accurate $\mathrm{pH}$ is measured online by a postdetector $\mathrm{pH}$ electrode/cell (Lazar Research Laboratories, Los Angeles, CA, USA) with low dead volume. Fractions were collected every $0.2 \mathrm{pH}$ unit change from $\mathrm{pH} 7.0$ to 4.0. Fractions of $\mathrm{pH} 6.0$ 4.6 were selected for further study due to the higher protein concentrations in these fractions.

\subsection{NPS-RP-HPLC with sample collection}

Following the CF fractionation, NPS-RP-HPLC is used to separate each fraction collected from the first dimension. High separation efficiency is achieved by using an ODSIII-E $(4.6 \mathrm{~mm} \times 33 \mathrm{~mm})$ column (Eprogen, Darien, IL) packed with $1.5 \mu \mathrm{m}$ nonporous silica. To collect purified proteins from NPS-RP-HPLC, the RP separation is performed at $0.5 \mathrm{~mL} / \mathrm{min}$ and monitored at $214 \mathrm{~nm}$ using a Beckman 166 Model UV detector (Beckman-Coulter, Fullerton, CA, USA). Proteins eluting from the column were collected by an automated fraction collector (Model SC 100, Beckman), controlled by an in-house designed DOS-based software program. To enhance the speed, resolution, and reproducibility of the separation, the RP column is heated to $60^{\circ} \mathrm{C}$ by a column heater (Jones Chromatography, Model 7971). Both mobile phase A (water) and B (ACN) contains $0.1 \% \mathrm{v} / \mathrm{v}$ TFA. The gradient profile used is as follows: $5-15 \% \mathrm{~B}$ in $1 \mathrm{~min}$, $15-25 \% \mathrm{~B}$ in $2 \mathrm{~min}, 25-31 \% \mathrm{~B}$ in $3 \mathrm{~min}, 31-41 \% \mathrm{~B}$ in $10 \mathrm{~min}, 41-47 \% \mathrm{~B}$ in $3 \mathrm{~min}, 47-67 \% \mathrm{~B}$ in $4 \mathrm{~min}$, and $67-$ $100 \%$ B in $1 \mathrm{~min}$. Deionized water was purified using a Millipore RG system (Bedford, MA, USA).

\subsection{NPS-RP-HPLC-online-ESI-TOF-MS}

To map the proteins in the cell lysate, fractions obtained from CF were subject to NPS-RP-HPLC separation with online ESI-TOF-MS detection. The separation was performed under the same condition as in Section 2.4 except that $0.3 \%$ formic acid (Sigma) was added to both mobile phases to improve the ESI efficiency. The flow rate was maintained at $0.5 \mathrm{~mL} / \mathrm{min}$ and a postcolumn splitter was used so that $200 \mu \mathrm{L} / \mathrm{min}$ was directed into an orthogonal acceleration ESI-TOF-MS (LCT; Micromass/Waters, Milford, MA, USA). The capillary voltage for electrospray was set at $3200 \mathrm{~V}$, sample cone at $35 \mathrm{~V}$, extraction cone at $3 \mathrm{~V}$, and reflection lens at $750 \mathrm{~V}$. Desolvation was accelerated by maintaining the desolvation temperature at $320^{\circ} \mathrm{C}$ and source temperature at $130^{\circ} \mathrm{C}$. The desolvation gas flow was $650-800 \mathrm{~L} / \mathrm{h}$. One microgram bovine insulin (Sigma) was introduced to each sample as an internal standard. The intact molecular weight value was obtained by deconvoluting the combined ESI spectra with maximum entropy deconvolution algorithm (MaxEnt1) software.

\subsection{Tryptic digestion}

Each fraction obtained from NPS-RP-HPLC (Section 2.4) was concentrated down to $\sim 20 \mu \mathrm{L}$ with a SpeedVac concentrator (Labconco, Kansas City, MO) operating at $60^{\circ} \mathrm{C}$. Twenty microliters of $100 \mathrm{mM}$ ammonium bicarbonate (Sigma) was then mixed with each concentrated sample to obtain a $\mathrm{pH}$ value of about 7.8. About $0.5 \mu \mathrm{L}$ of L-1-tosylamido-2-phenylethyl chloromethylketone (TPCK) modified sequencing-grade porcine trypsin (Promega, Madison, WI) was added and vortexed prior to a $20-\mathrm{h}$ incubation at $37^{\circ} \mathrm{C}$ on an agitator.

\subsection{MALDI sample preparation}

Before MALDI analysis, each digested sample was desalted and concentrated to $5 \mu \mathrm{L}$ using C18 ZipTip (Millipore). One microliter of the concentrated peptide mixture was spotted onto a Micromass 96-spot plate followed by $1 \mu \mathrm{L}$ of matrix-standard layered on top of it. The MALDI matrix was prepared by diluting saturated $\alpha$-CHCA (Sigma) solution with $50 \% \mathrm{v} / \mathrm{v}$ ACN and $1 \% \mathrm{v} / \mathrm{v}$ TFA at $1: 4$ ratio $\mathrm{v} / \mathrm{v}$. About $1 \mathrm{mg} / \mathrm{mL}$ angiotensin I (1296 Da), adrenocorticotropic hormone (ACTH clip 1-17, $2093 \mathrm{Da}$ ), and ACTH clip 18-39 (2465 Da) (Sigma) were diluted 100 -fold with deionized water. These standards were further diluted 50, 40, and 30 times, respectively, with the diluted matrix.

\subsection{PMF}

In order to identify proteins in each fraction collected from NPS-RP-HPLC, MALDI-TOF-MS analysis was performed for each digested sample. With internal standards and delayed extraction reflectron TOF-MS (TOF Spec 2E, Micromass), a mass accuracy of less than $30 \mathrm{ppm}$ can be consistently achieved. Monoisotopic masses of peptides were selected and searched against Swiss-Prot using MS-Fit http://prospector. 
ucsf.edu/ucsfhtml4.0/msfit.htm. The following parameters were used in the search: (1) species: human; (2) maximum number of missed cleavage: 1; (3) possible modifications: peptide $\mathrm{N}$-termal glutamine to pyro-glutamic acid, oxidation of methionine, and protein $\mathrm{N}$-terminus acetylated; (4) peptide mass tolerance $50 \mathrm{ppm}$; (5) $M_{\mathrm{r}}$ of protein: 1000$100000 \mathrm{Da}$; (6) pI range of protein 3-10. Only protein IDs with sequence coverage higher than $15 \%$ and MOWSE scores over 1000 were considered.

\subsection{MALDI-TOF/TOF analysis of protein digests}

To confirm the proteins identified by PMF and to identify proteins with low sequence coverage, MS/MS spectra were acquired for selected peptides using MALDI-TOF/TOF-MS (Q-Applied Biosystems, Foster City, CA, USA). About $0.5 \mu \mathrm{L}$ aliquot of peptide solution was spotted on to an Applied Biosystems 192-spot plate covered by $0.5 \mu \mathrm{L}$ matrix. According to the MALDI-TOFMS data, eight peptides were selected from each spot for fragmentation. Collision energy was set at $1 \mathrm{kV}$. Ions with a mass window of $\pm 4 \mathrm{Da}$ were selected in the TOF/TOF timed ion selector. The MS/MS spectra was acquired and processed using 4700 Explorer. MASCOT was used to search the database. The parent ion mass tolerance was $60 \mathrm{ppm}$ and the daughter ion mass tolerance was set to $0.3 \mathrm{Da}$. One missed cleavage was allowed and the possible modifications were $\mathrm{N}$-acetyl, oxidation of methionine, phosphorylation of serine, threonine and tyrosine, and pyro-glu at $N$-term glutamine and glutamic acid.

\subsection{Western blot analysis}

Total cell lysates from MCF10AT1 and MCF10AT1E2 cells were prepared in $10 \mathrm{mM}$ Tris- $\mathrm{HCl}, \mathrm{pH} 7.5 / 150 \mathrm{mM} \mathrm{NaCl} / 1 \%$ Triton X-100/1 mM PMSF, $1 \mu \mathrm{g} / \mathrm{mL}$ each of leupeptin, pepstatin, antipain, and $1 \mathrm{mM}$ sodium orthovanadate. Proteins $(50 \mu \mathrm{g})$ from each cell lysate were separated by SDS-PAGE and transblotted onto Immobilon P membranes. Steady-state levels of Grp75 were determined by reacting the membrane with antiGrp75 mouse mAb (Abcam), and immunoreactive bands were visualized by chemiluminescence using ECL kit (Perkin Elmer). Equivalent aliquots of MCF10AT1 or MCF10AT1E2 protein fractions eluted from CF column ( $\mathrm{pH}$ 4.6-6.0) were desalted and concentrated by filtration through Ultra free-MC 10K NMWL filter unit (Millipore), and subjected to SDS-PAGE and Western blot analysis of Grp75 as described above. Band intensities were quantitated with a Model 300A densitometer (Molecular Dynamics, Sunnyvale, CA).

\section{Results and discussion}

\subsection{Cells}

MCF10AT1 is derived from MCF10A by T-24 c-Ha-ras gene transfection. It is premalignant, but can develop into xenograft lesions spanning the spectrum from normal, atypical hyper- plasia, ductal carcinoma in situ (DCIS), and invasive carcinomas. It truly represents early breast cancer progression since the human cell line MCF10A originated from spontaneous immortalization of breast epithelial cells obtained from a single patient with fibrocystic disease. Although E2 is not required for the formation and progression of MCF10AT1 lesions, it does accelerate progression in the xenografts formed [18]. The MCF10AT1 cells express ER (Er $\alpha$ ) in vitro [19]. Thus, the analysis of proteins in MCF10AT1 and the E2treated MCF10AT1E2 can reveal some key estrogen-regulated proteins which are involved in cancer progression.

\subsection{Liquid-phase 2-D separation online ESI-TOF-MS analysis}

Protein profiling techniques include 2-DE, liquid-phase IEF followed by RP separation online MS detection and the recently developed liquid 2-D separation based upon CF and RP separation, with UV detection. In this work, MCF10AT1 and MCF10AT1E2 cell lysates were separated with CF in the first dimension. The collected fractions were further separated by NPS-RP-HPLC and detected online using ESI-TOF-MS. The liquid-based method has the advantage of minimized sample handling, compatibility to MS analysis, improved recovery and reproducibility, improved resolution in the $\mathrm{pH}$ dimension, and fraction collection of proteins for further analysis. Online ESITOF-MS detection provides high mass accuracy, MW measurements, specificity, and accurate quantitation.

CF separates proteins according to the $\mathrm{p} I$. It is a single chromatographic focusing procedure that combines the high capacity of ion-exchange chromatography with the high resolution of IEF. A typical CF chromatogram is shown in Fig. 1, where $4.7 \mathrm{mg}$ cell extract from MCF10AT1E2 was fractionated. As shown, the change of $\mathrm{pH}$ at the outlet of column over time is linear from $\mathrm{pH} 7$ to 4 . In order to balance the resolution in the $\mathrm{pH}$ dimension and the number of fractions collected for further analysis, each fraction was collected with a $0.2 \mathrm{pH}$ change. Over the course of a 60-min CF separation, a total of 15 fractions were obtained.

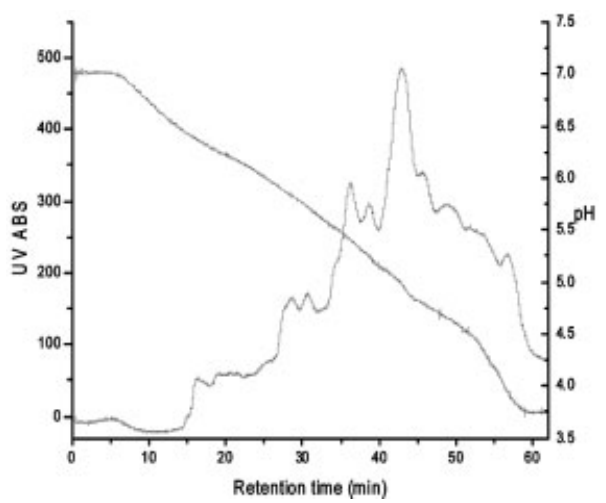

Figure 1. CF-UV chromatogram of $4.7 \mathrm{mg}$ lysed AT1E2 cells. Flow rate $=0.2 \mathrm{~mL} / \mathrm{min}$. UV absorption was set at $280 \mathrm{~nm}$. 

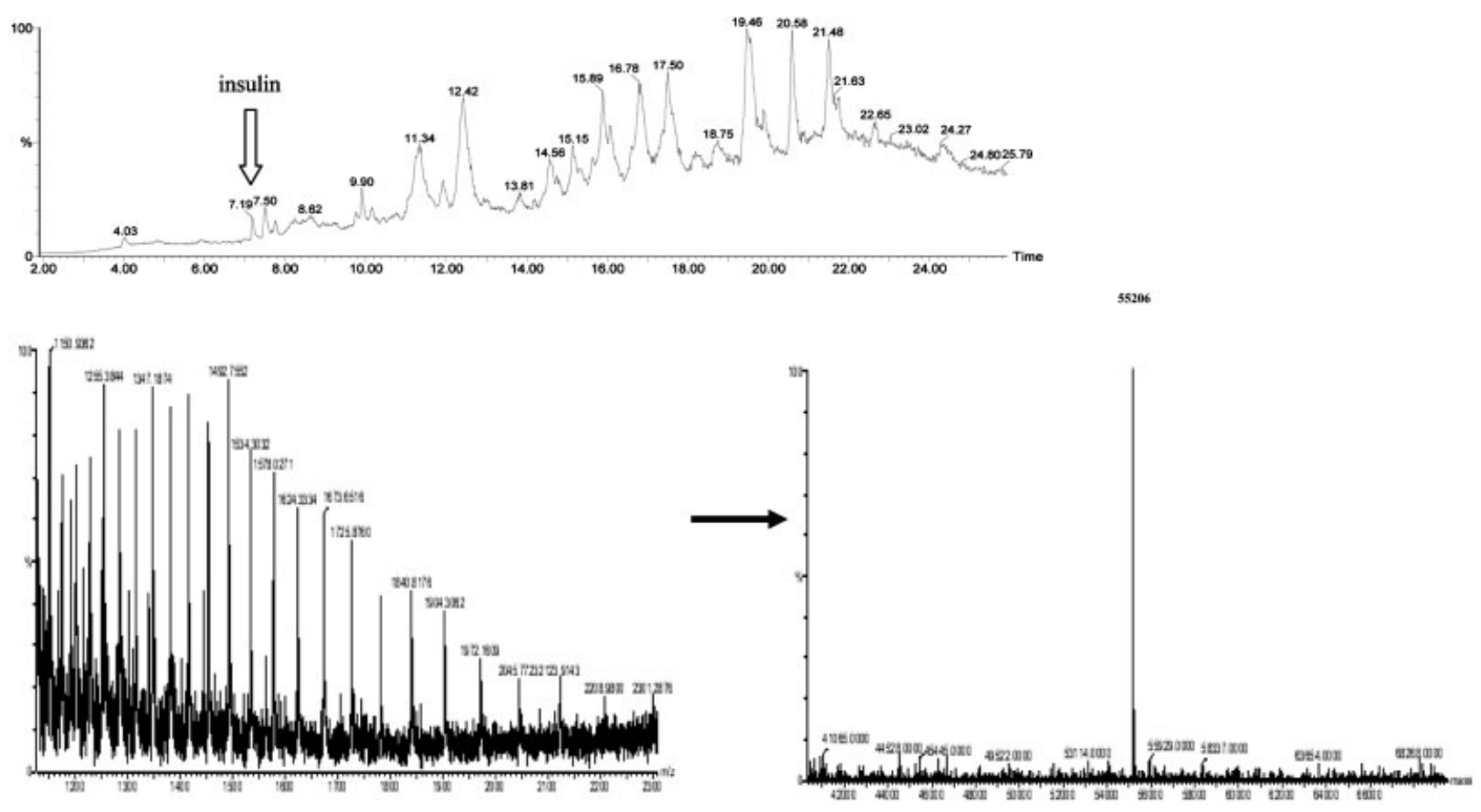

Figure 2. (a) NPS-RP-HPLC/ESI-MS-TIC chromatogram of CF fraction \#8 (pH 5.4-5.2). One microgram bovine insulin was added as internal standard. (b) Combined mass spectra of the circled peak in Fig. 2a. MW was determined after deconvolution of a series of multiply charged ion peaks. This protein was identified as ATP synthase alpha chain. Experimental $M_{\mathrm{r}}\left(\right.$ Exp. $\left.M_{\mathrm{r}}=55206\right)$ matched the theoretical $M_{\mathrm{r}}$ of the truncated form (Theo. $M_{\mathrm{r}}=55209$ ).

Fractions of $\mathrm{pH}$ 4.6-6.0 were further analyzed by NPSRP-HPLC-online-ESI-TOF-MS. A total ion chromatogram of the LC-MS analysis for the MCF10AT1 fraction with $\mathrm{pH}$ 5.45.2 is shown in Fig. 2a. Proteins remain intact during the separation and MS analysis. During the 30 min separation, one spectrum is acquired per second. In order to obtain the MW of intact proteins, a series of multiply charged ion peaks in the combined spectrum (as shown in Fig. 2b) is deconvoluted. The theoretical mass of the protein, truncated ATP synthase alpha chain, is $55209 \mathrm{Da}$. It is only $3 \mathrm{Da}$ higher than the experimental MW of $55206 \mathrm{Da}$, which suggests a mass accuracy of $50 \mathrm{ppm}$.

The abundance of each protein is indicated by the peak area of the deconvoluted peak of the intact protein. The entire amount of a protein present in each CF fraction can be obtained by deconvoluting the combined spectra of a selected ion chromatogram (SIC) created for the protein. To minimize the quantitation error induced by experimental variation, all peak areas obtained in a single LC-MS analysis were normalized to the deconvoluted peak area of insulin that was introduced as an internal standard.

\subsection{2-D mass map}

A mass map is created by integrating the MW, pI, and the abundance for all proteins in all CF fractions into one single image using ProteoVue or DeltaVue software. One such map is shown in Fig. 3a. The mass map resulted from the integration of the MW, $\mathrm{pI}$, and abundance of all proteins in seven $\mathrm{CF}$ fractions with $\mathrm{pH}$ varying from 4.6 to 6.0. The map to the left is for MCF10AT1 cells, and the one to the right is for MCF10AT1E2 cells. In the visual 2-D map, the $\gamma$-axis represents MW and $x$-axis represents $\mathrm{pH}$. Each protein is shown as a band on the map with the intensity of the band indicating the abundance.

The 2-D map provides an overview of protein mass distribution and composition in each fraction in a pattern similar to 2-D PAGE. Moreover, differentially expressed proteins in the samples with and without estrogen treatment can be displayed, as shown in the middle of Fig. 3a. As a result, the complexity of a large number of proteins could be reduced to a virtual map and protein expression levels can be easily compared. The reproducibility of the protein profiling method is demonstrated in Fig. 4, where two differential maps of four CF fractions with $\mathrm{pH}$ 4.6-5.6 from two duplicate experiments are displayed.

\subsection{Protein identification}

From the CF-NPS-RP-HPLC online ESI-TOF-MS analysis, the MW, $\mathrm{pI}$, and abundance information can be obtained. However, the protein identity is still unknown. Therefore, a separate NPS-RP-HPLC is conducted for each CF fraction using an identical gradient monitored by a UV detector and 

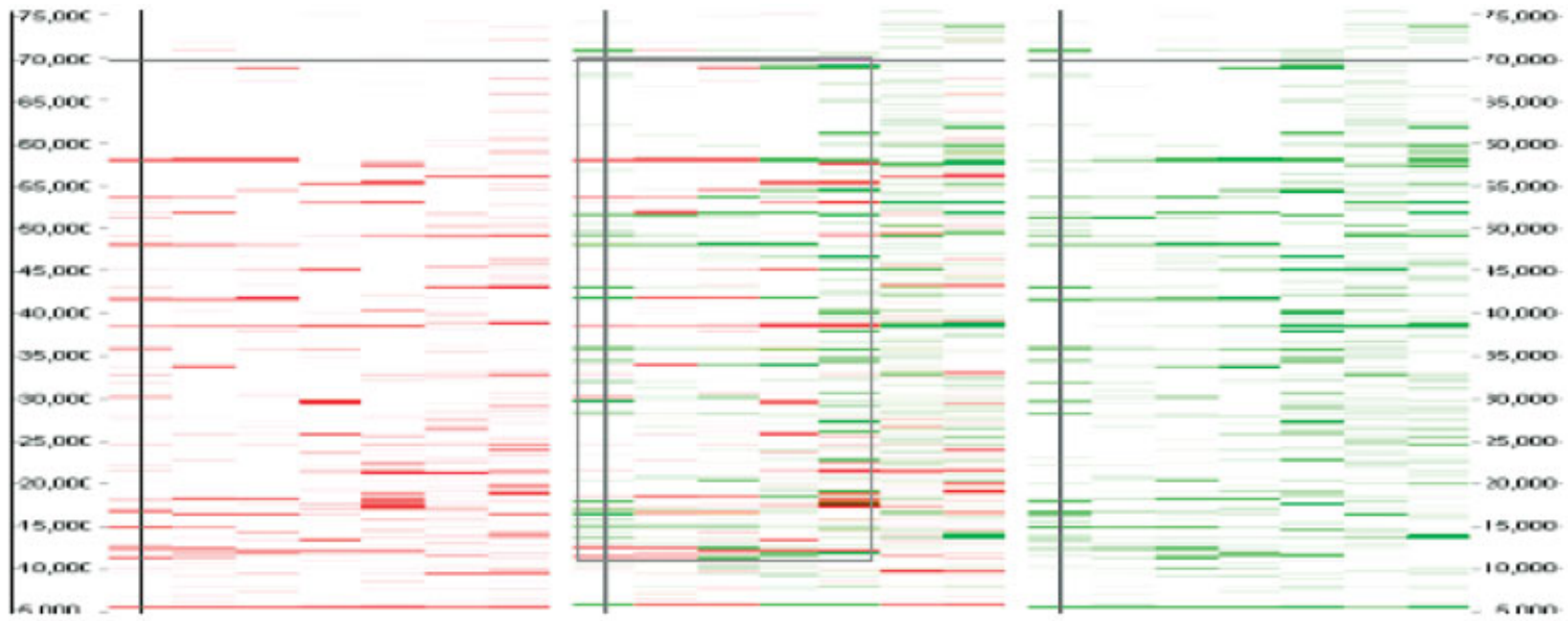

pH

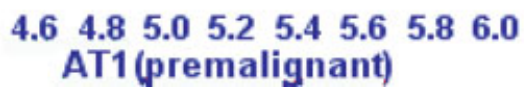

\section{$4.64 .85 .05 .25 .45 .65 .8 \quad 6.0$ AT1E2 (estrogen treated)}

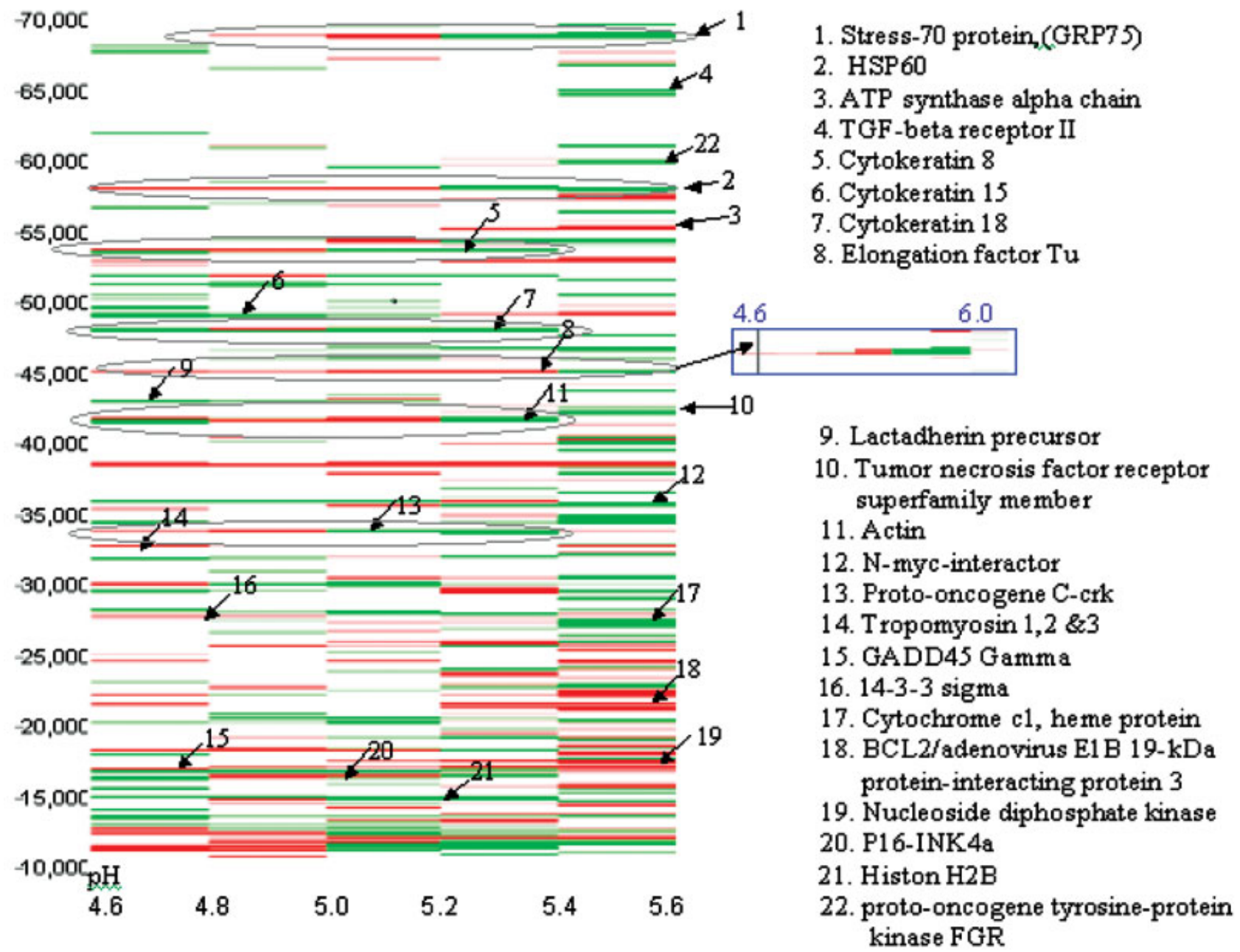

Figure 3. (a) 2-D mass map of cell line MCF10AT1 (left) and MCF10AT1E2 (right) in pH range 4.6-6.0 and $M_{\mathrm{r}}$ range 5-75K. Differential map shown in the middle is generated by point subtraction. (b) Differential map between the two samples was zoomed in to $\mathrm{pH} 4.6-5.6$ and $M_{\mathrm{r}} 10-70 \mathrm{~K}$. Some mass map-correlated protein IDs were labeled. 

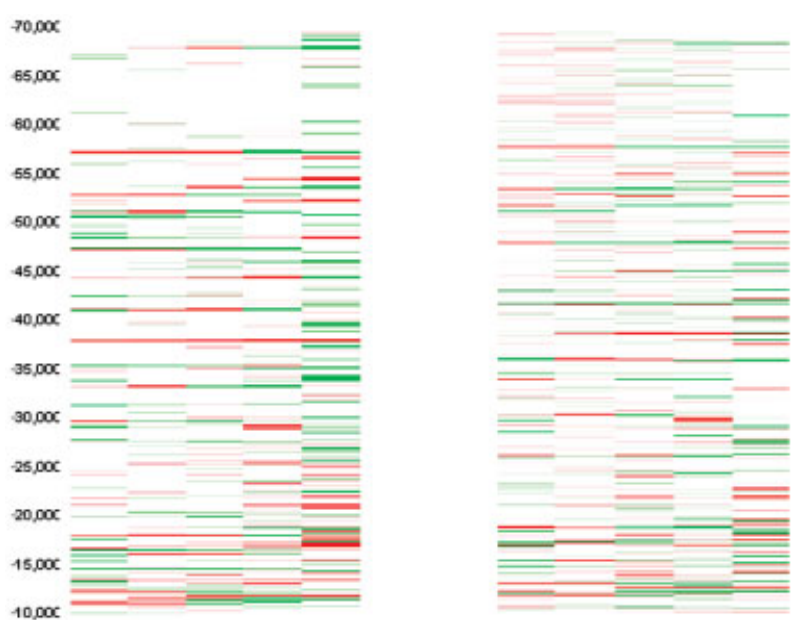

Figure 4. CF-LC-ESI-MS experiments were repeated three times independently and the mass maps were generated. Two differential maps in $\mathrm{pH} 4.6-5.6$ were selected to show the reproducibility.

followed by fraction collection. The collected fractions from RP separation were concentrated, digested, and analyzed by MALDI-TOF-MS or MALDI-TOF/TOF-MS for identification. The protein ID can be correlated to the MW and abundance observed in ESI-TOF-MS using retention time in the RP separation. In this work, $\sim 300$ proteins were identified by PMF or sequencing; 120 were detected by ESI-MS and assigned to a band on the mass map.

One disadvantage of PMF is that it biases against proteins with low molecular weight and proteins with low abundance [20], where only limited number of peptides can be detected. This problem can be overcome by MS/MS analysis and the MW of the intact protein obtained from ESI-TOF-MS analysis. Therefore, peptides from proteins with ambiguous identification, unassigned peptides with quality MS signals, and peptides with possible modifications were selected for MALDITOF/TOF analysis. In the case of the protein enhancer of rudimentary homolog, a protein $M_{\mathrm{r}} 12$ 259, when analyzed by MALDI-TOF-MS, only two peaks were matched as shown in Fig. 5a, which is insufficient for identification. However, the MS/MS analysis revealed its identity (as shown in Fig. 5b and c) which was confirmed by the MW obtained from the ESITOF-MS analysis.

The MW and $\mathrm{pI}$ of intact proteins acquired in protein profiling using CF-NPS-RP-HPLC-online-ESI-TOF-MS are useful not only in protein ID confirmation but also in revealing PTMs. A difference between the experimental $\mathrm{MW} / \mathrm{pI}$ and the theoretical MW/pI is often due to modifications such as truncation and phosphorylation [21]. Some of the proteins identified in this work are categorized in Tables 1-4. Most experimental MW values match well with their corresponding theoretical MW. However, there are some discrepancies in each of the four tables. All the proteins with MW shifts due to truncation are listed in Table 5.

\subsection{Differentially expressed proteins after E2 treatment}

To identify differentially expressed proteins in these two samples, the mass map of MCF10AT1 and that of MCF10AT1E2 can be overlayed using DeltaVue as shown in Fig. 3b. The red bands are from AT1, and the green bands are from AT1E2. Approximately 40 proteins were detected in each CF fraction by ESI-MS analysis in the mass range $5-75 \mathrm{kDa}$. Proteins expressed at lower levels might not be observed due to limitations in instrument sensitivity and data processing software. Approximately $70 \%$ of the proteins detected are present in both untreated and estrogen-treated cells.

The band intensity indicates the abundance of proteins. However, some high-abundance proteins may appear in more than one CF fraction. On the differential mass map, they are displayed as one wide band covering several $\mathrm{pH}$ sections. For example, the theoretical pI of cleaved HSP 60 (band 2) has a theoretical pI of 5.6 - but it was detected from pH 4.6 to 5.6 - while cytokeratin 18 (band 7) and actin (band 11) have theoretical pI of 5.3 and 5.2, respectively; however, they were detected from $\mathrm{pH} 4.6$ to 5.4. To determine the total quantity of these high-abundance proteins, the peak area of each protein in each CF fraction must be summed together to estimate the total amount of the protein in one cell line. In this study, about 120 proteins were selected for quantitation. These proteins, which have highintensity bands on the massmap, have been detected in at least two experiments and firmly identified.

To obtain reliable quantitation, three duplicate CF-NPSRP-HPLC-online-ESI-TOF-MS analyses were performed for MCF10AT1 and MCF10AT1E2 cell lysates. The peak area of each of the deconvoluted intact proteins was normalized to that of insulin. The mean and SD of the normalized peak areas obtained from duplicate experiments were calculated for each protein and are shown in Tables $1-3$. A SD of $10 \%$ can be achieved for high-abundance proteins, while 10$30 \%$ SD can be realized for low-abundance proteins. Among the differentially expressed proteins, $70 \%$ of them were detected in duplicate experiments. In some cases, proteins are only detected in two duplicate experiments. Therefore, SDs are not available. Alternatively, the average of their normalized protein expressions was used.

\subsubsection{Proteins with no obvious changes in expression}

Proteins detected in both MCF10AT1 and MCF10AT1E2 lysate are listed in Table 3. These proteins were all firmly identified by PMF, MS/MS, or both. The measured MW of intact proteins all matched well with their corresponding theoretical MW value. As listed, the normalized peak area for each protein in MCF10AT1 and MCF10AT1E2 were shown in separate columns. The change of each protein was calculated by dividing the normalized peak area obtained from MCF10AT1E2 by that obtained from MCF10AT1. Among the 74 proteins listed, actin (alpha, beta, and gamma) and ATP synthase remain unchanged upon estrogen treatment. It is 

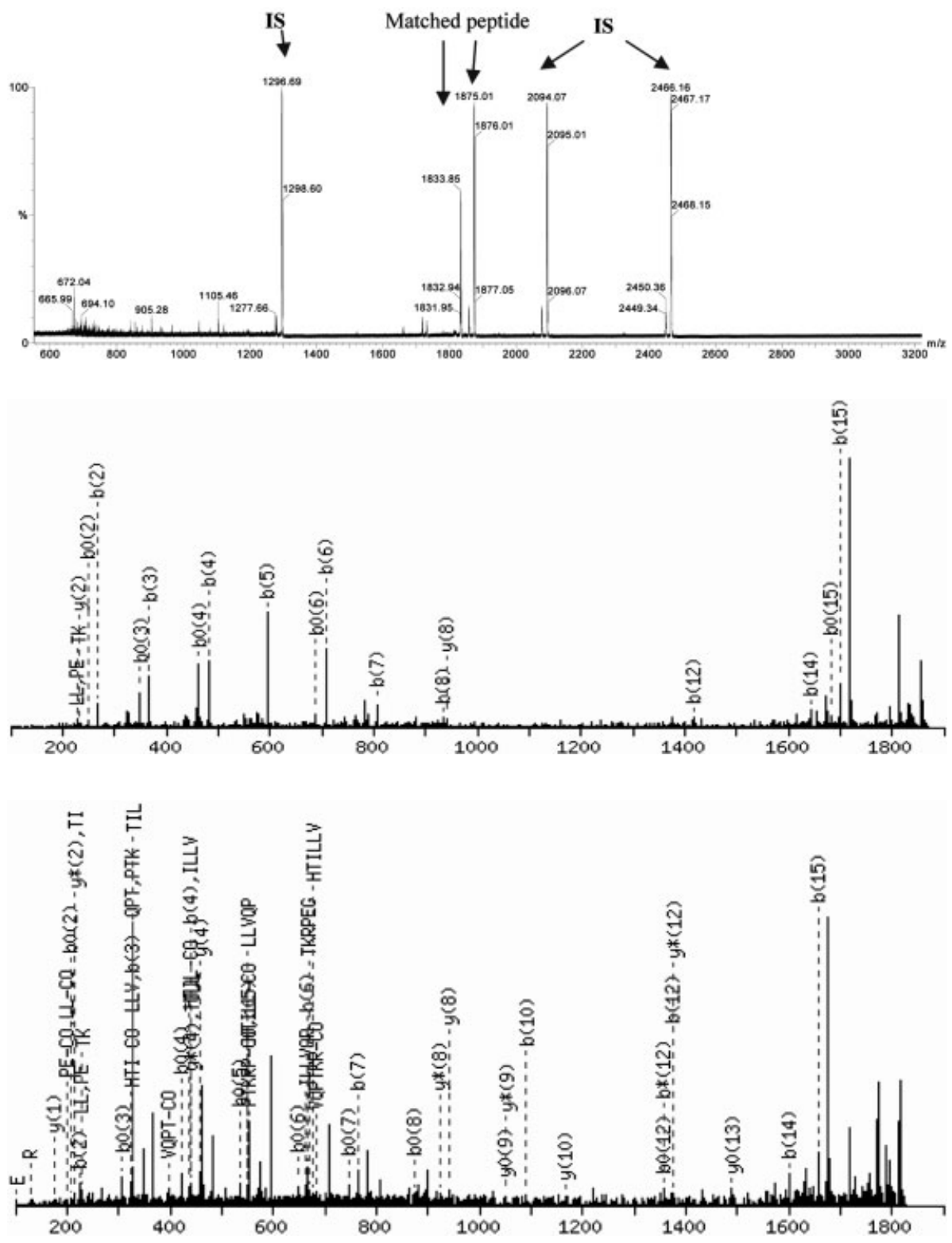

Figure 5. (a) MS spectrum of enhancer of rudimentary homolog (Q14259) after trypsin digestion. Identification is ambiguous because of the low number of peptides detected. Three peptides were added in the matrix as internal standards with $\mathrm{m} / \mathrm{z}$ of 1296, 2093 , and 2465. (b) MS/MS spectrum of the peptide at $\mathrm{m} / \mathrm{z}$ of 1874 was obtained by using MALDI-TOF-TOF. Sequence is SHTILLVQPTKRPEGR + acetyl ( $N$ term). (c) MS/MS spectrum of the peptide at $\mathrm{m} / \mathrm{z}$ of 1832 . Sequence is SHTILLVOPTKRPEGR. Both of these two sequences were confidently identified as Enhancer of rudimentary homolog (014259).

worthwhile to point out that actin isoforms were resolved despite their close MW, $\mathrm{p}$, and the low expression of $\alpha$-actin. Further, many of these proteins are expressed in high levels in both cell lines. Western blot analysis of $\beta$-actin levels in whole cell lysates and fractions collected from CF columns from control untreated (panel A) and estrogen-treated (panel B) MCF10AT cells are shown in Fig. 6. The results confirm that the total amounts of this housekeeping protein in unfractionated samples and individual fractions are similar
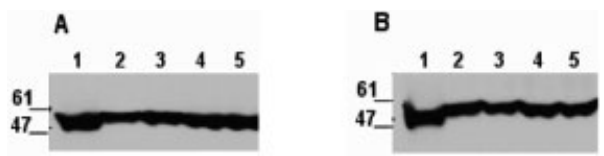

Figure 6. Western blot analysis of $\beta$-actin levels in fractions collected from CF columns from control untreated (panel A) and estrogen-treated (panel B) MCF10AT cells. Lane 1, total cell lysate; lane 2, pH 4.6-4.8; lane 3, 4.8-5.0; lane 4, 5.0-5.2; lane 5, 5.2-5.4. 
Table 1. Proteins only detected in MCF10AT1E2 by ESI-MS

\begin{tabular}{|c|c|c|c|c|c|c|}
\hline \multirow[t]{2}{*}{ Acc \# } & \multirow[t]{2}{*}{ Protein ID } & \multirow{2}{*}{$\begin{array}{l}\text { Theo } \\
\text { MW/pl }\end{array}$} & \multirow[t]{2}{*}{ Exp MW } & \multirow{2}{*}{$\frac{\text { Identification }}{\text { Method }}$} & \multirow{2}{*}{$\frac{\text { Expression }}{\text { In AT1E2 } 2^{\text {b) }}}$} & \multirow[t]{2}{*}{ Change $^{\text {a) }}$} \\
\hline & & & & & & \\
\hline 075791 & GRB2-related adaptor protein 2 & $37910 / 6.4$ & 37901 & PMF & $0.14 \pm 0.03$ & $27 \pm 5$ \\
\hline 013976 & cGMP-dependent protein kinase 1, alpha isozyme & $76365 / 5.7$ & 76422 & PMF & $0.13 \pm 0.02$ & $27 \pm 3$ \\
\hline P46108 & Proto-oncogene C-crk (P38) & $22936 / 5.2$ & 22940 & PMF & $0.116 \pm 0.015$ & $23 \pm 3$ \\
\hline 014763 & Tumor necrosis factor receptor superfamily member $10 \mathrm{~B}$ & $42202 / 5.0$ & 42161 & PMF & $0.120 \pm 0.013$ & $23 \pm 3$ \\
\hline 095881 & Thioredoxin-like protein p19 precursor & $16426 / 5.2$ & 16435 & PMF & $0.09 \pm 0.01$ & $18 \pm 2$ \\
\hline 015642 & Cdc42-interacting protein 4 (Thyoid receptor interacting protein 10) & $62592 / 5.2$ & 62595 & PMF & $0.06 / 0.11$ & 17 \\
\hline P13646 & Keratin, type I cytoskeletal 13 (Cytokeratin 13) (K13) & $49587 / 4.9$ & 49586 & PMF & $0.08 \pm 0.02$ & $16 \pm 3$ \\
\hline Q8NBS9 & Thioredoxin domain containing protein 5 [Precursor] & $47629 / 5.8$ & 47697 & MS/MSPMF & $0.08 \pm 0.01$ & $15 \pm 2$ \\
\hline P37173 & TGF-beta receptor type II & $64540 / 5.6$ & 64709 & PMF & $0.05 / 0.1$ & 15 \\
\hline P09769 & Proto-oncogene tyrosine-protein kinase FGR (P55-FGR) & $59479 / 5.4$ & 59509 & PMF & $0.05 / 0.08$ & 13 \\
\hline Q9BZD7 & Transmembrane gamma-carboxyglutamic acid protein 3 & $23650 / 5.3$ & 23650 & PMF & $0.06 \pm 0.02$ & $12 \pm 3$ \\
\hline P04155 & Trefoil factor 1 [Precursor] & $9150 / 4.3$ & 9165 & PMF & $0.06 \pm 0.01$ & $11 \pm 2$ \\
\hline 099426 & Tubulin-specific chaperone B & $27326 / 5.1$ & 27373 & PMF & $0.04 / 0.07$ & 11 \\
\hline P40616 & ADP-ribosylation factor-like protein 1 & $20418 / 5.6$ & 20410 & PMF & $0.05 \pm 0.02$ & $10 \pm 3$ \\
\hline P10109 & Adrenodoxin, mitochondrial precursor & $13561 / 4.4$ & 13577 & PMF & $0.05 \pm 0.01$ & $10.0 \pm 1.9$ \\
\hline 013287 & $\mathrm{~N}$-myc-interactor (Nmi) (N-myc and STAT interactor) & $35117 / 5.2$ & 35943 & PMF & $0.03 / 0.07$ & 10 \\
\hline 09U080 & Proliferation-associated protein $2 \mathrm{G} 4$ & $43787 / 6.1$ & 43814 & PMF & $0.04 / 0.06$ & 10 \\
\hline P53667 & LIM domain kinase 1 & $72602 / 6.5$ & 72850 & PMF & $0.047 \pm 0.008$ & $9 \pm 2$ \\
\hline P11021 & $78 \mathrm{kDa}$ glucose-regulated protein precursor (GRP 78) & $70478 / 5.0$ & 70874 & MS/MSPMF & $0.04 \pm 0.01$ & $8 \pm 2$ \\
\hline 092843 & Apoptosis regulator Bcl-W (Bcl-like 2 protein) & $20775 / 5.4$ & 20706 & PMF & $0.033 \pm 0.007$ & $7 \pm 1$ \\
\hline P01106 & Myc proto-oncogene protein (c-myc) & $48804 / 5.3$ & 48828 & PMF & $0.008 / 0.014$ & 7 \\
\hline P24385 & G1-S-specific cyclin D1(PRAD1 oncogene) & $33729 / 5.0$ & 33705 & PMF & $0.03 \pm 0.01$ & $5 \pm 2$ \\
\hline 013509 & Tubulin beta- 4 chain (Tubulin beta-III) & $50433 / 4.8$ & 50481 & PMF & $0.023 \pm 0.005$ & $5 \pm 1$ \\
\hline P08107 & Heat shock $70 \mathrm{kDa}$ protein 1 (HSP70.1) & $70053 / 5.5$ & 70086 & MS/MSPMF & $0.022 / 0.016$ & 3.8 \\
\hline
\end{tabular}

a) Standard deviation obtained from 3 replicate experiments is indicated. The protein quantity change without STD is the average of two replicate experiments.

The undetected protein level in LC-ESI-TOF MS experiment is assumed as the same with the lowest expression level detected using this instrument (WT1-associated protein in MCF10AT1 cell line). The expression change between detected and undetected expression is calculated on this basis.

b) The mean value of protein expression and the standard deviation obtained from 3 replicate experiments are indicated. For the proteins in which only two values are available, both values are reported.

Table 2. Proteins only detected in MCF10AT1 by ESI-MS

\begin{tabular}{|c|c|c|c|c|c|c|}
\hline \multirow[t]{2}{*}{ Acc \# } & \multirow[t]{2}{*}{ Protein ID } & \multirow{2}{*}{$\begin{array}{l}\text { Theo } \\
\text { MW/pl }\end{array}$} & \multirow[t]{2}{*}{ Exp MW } & \multirow{2}{*}{$\frac{\text { Identification }}{\text { Method }}$} & \multirow{2}{*}{$\frac{\text { Expression }}{\ln A T 1^{\text {b) }}}$} & \multirow[t]{2}{*}{ Change $^{\text {al }}$} \\
\hline & & & & & & \\
\hline P12074 & Cytochrome c oxidase polypeptide Vla-liver, mitochondrial [Precursor] & $9619 / 6.4$ & 9619 & MS/MSPMF & $0.67 \pm 0.18$ & $<-50$ \\
\hline P55809 & $\begin{array}{l}\text { Succinyl-CoA:3-ketoacid-coenzyme A transferase 1, mitochondrial } \\
\text { precursor }\end{array}$ & $56158 / 7.1$ & 56157 & PMF & $0.19 \pm 0.01$ & $-38 \pm 2$ \\
\hline 012983 & BCL2/adenovirus E1B 19-kDa protein-interacting protein 3 & $21541 / 6.3$ & 21542 & PMF & $0.18 \pm 0.03$ & $-35 \pm 5$ \\
\hline P80188 & Neutrophil gelatinase-associated lipocalin precursor (NGAL) & $22588 / 9.0$ & 22553 & PMF & $0.17 \pm 0.02$ & $-35 \pm 4$ \\
\hline 043402 & neighbor of $\mathrm{COX} 4$ & $23779 / 5.9$ & 23775 & PMF & $0.11 \pm 0.02$ & $-23 \pm 3$ \\
\hline P21266 & Glutathione S-transferase Mu 3 (GSTM3-3) (GST class-mu 3) (hGSTM3-3) & $26560 / 5.4$ & 26571 & MS/MSPMF & $0.09 \pm 0.01$ & $-18 \pm 2$ \\
\hline 095257 & Growth arrest and DNA-damage-inducible protein GADD45 gamma & $17121 / 4.3$ & 17070 & PMF & $0.084 \pm 0.014$ & $-17 \pm 3$ \\
\hline 013162 & Peroxiredoxin & $30540 / 5.9$ & 30545 & MS/MSPMF & $0.062 \pm 0.010$ & $-12 \pm 2$ \\
\hline P09493 & Tropomyosin 1 alpha chain & $32709 / 4.7$ & 32831 & MS/MSPMF & $0.057 \pm 0.009$ & $-11 \pm 2$ \\
\hline P08727 & Keratin, type I cytoskeletal 19 (Cytokeratin 19) (K19) (CK 19) & $44106 / 5.0$ & 44121 & PMF & $0.04 \pm 0.01$ & $-8 \pm 2$ \\
\hline P14866 & Heterogeneous nuclear ribonucleoprotein L (hnRNP L) & $60188 / 6.7$ & 60189 & MS/MSPMF & $0.042 / 0.035$ & -8 \\
\hline P13693 & $\begin{array}{l}\text { Translationally controlled tumor protein (TCTP) (p23) } \\
\text { (Histamine-releasing factor) (HRF) }\end{array}$ & $19596 / 4.8$ & 19610 & MS/MSPMF & $0.021 / 0.032$ & -5 \\
\hline P27348 & $\begin{array}{l}\text { 14-3-3 protein tau (14-3-3 protein theta) (14-3-3 protein T-cell) } \\
\text { (HS1 protein) }\end{array}$ & $27764 / 4.7$ & 27699 & PMF & $0.014 / 0.023$ & -4 \\
\hline
\end{tabular}


Table 3. Proteins detected in MCF10AT1 and MCF10AT1E2 by ESI-MS

\begin{tabular}{|c|c|c|c|c|c|c|c|}
\hline \multirow[t]{2}{*}{ Acc \# } & \multirow[t]{2}{*}{ Protein ID } & \multirow{2}{*}{$\begin{array}{l}\text { Theo } \\
\text { MW/pl }\end{array}$} & \multirow{2}{*}{$\begin{array}{l}\text { Exp } \\
\text { MW }\end{array}$} & \multirow{2}{*}{$\frac{\text { Identification }}{\text { Method }}$} & \multirow{2}{*}{$\frac{\text { Expression }}{\ln A T 1^{d)}}$} & \multirow{2}{*}{$\frac{\text { Expression }}{\ln \mathrm{AT}_{\mathrm{E}} 2^{\mathrm{e}}}$} & \multirow[t]{2}{*}{ Change $^{\mathrm{cl}}$} \\
\hline & & & & & & & \\
\hline 015007 & Wilm's tumor 1-associating protein (WT1-associated protein) & $17801 / 5.4$ & 17770 & PMF & $0.005 \pm 0.001$ & $0.12 \pm 0.03$ & $23 \pm 7$ \\
\hline P10599 & Thioredoxin (ATL-derived factor) (ADF) & $11738 / 4.8$ & 11742 & MS/MSPMF & $0.029 \pm 0.009$ & $0.52 \pm 0.13$ & $19 \pm 2$ \\
\hline P13645 & Keratin, type I cytoskeletal 10 (Cytokeratin 10) (K10) (CK 10) & $59519 / 5.1$ & 59533 & MS/MSPMF & $0.013 \pm 0.002$ & $0.23 \pm 0.003$ & $18.5 \pm 1.4$ \\
\hline 099757 & Thioredoxin, m.p. & $18383 / 8.5$ & 18403 & MS/MSPMF & $0.14 \pm 0.01$ & $2.5 \pm 0.5$ & $17 \pm 2$ \\
\hline Q9UBC7 & Galanin-like peptide precursor & $10118 / 6.3$ & 10128 & PMF & $0.012 \pm 0.003$ & $0.18 \pm 0.03$ & $15 \pm 2$ \\
\hline P62502 & EpididyImal-specific lipocalin 6 precursor (Lipocalin 5) & $18045 / 4.8$ & 18025 & PMF & $0.04 \pm 0.02$ & $0.52 \pm 0.18$ & $14 \pm 3$ \\
\hline P09382 & Galectin-1 (Beta-galactoside-binding lectin L-14-I) & $14716 / 5.3$ & 14711 & MS/MSPMF & $0.017 \pm 0.006$ & $0.2 \pm 0.1$ & $11 \pm 2$ \\
\hline P08729 & Keratin, type II cytoskeletal 7 (Cytokeratin 7) & $51418 / 5.5$ & 51460 & MS/MSPMF & $0.06 \pm 0.01$ & $0.66 \pm 0.25$ & $11 \pm 2$ \\
\hline 014696 & Mesoderm development candidate 2 & $26077 / 7.6$ & 26060 & PMF & $0.06 \pm 0.03$ & $0.6 \pm 0.2$ & $11 \pm 2$ \\
\hline P09758 & Tumor-associated calcium signal transducer 2 precursor & $35710 / 9.3$ & 35691 & PMF & $0.12 \pm 0.07$ & $1.1 \pm 0.4$ & $10 \pm 3$ \\
\hline P01609 & IG KAPPA CHAIN V-I REGION SCW & $11764 / 5.7$ & 11793 & PMF & $0.014 \pm 0.007$ & $0.13 \pm 0.03$ & $10 \pm 3$ \\
\hline 013242 & Splicing factor, arginine/serine-rich 9 & $25542 / 8.7$ & 25517 & MS/MSPMF & $0.01 \pm 0.002$ & $0.1 \pm 0.02$ & $10 \pm 2$ \\
\hline P38646 & Stress-70 protein, mitochondrial precursor (GRP75) & $68759 / 5.4$ & $\begin{array}{l}68763 / \\
68840\end{array}$ & MS/MSPMF & $1.2 \pm 0.3$ & $11.5 \pm 1.5$ & $10 \pm 1$ \\
\hline 043427 & Acidic fibroblast growth factor intracellular binding protein & $41878 / 6.0$ & 42033 & MS/MSPMF & $0.041 \pm 0.006$ & $0.37 \pm 0.13$ & $9 \pm 2$ \\
\hline P49411 & Elongation factor Tu, mitochondrial precursor (EF-Tu) (P43) & $45045 / 6.3$ & 45047 & MS/MSPMF & $0.7 \pm 0.3$ & $5.6 \pm 1.2$ & $9 \pm 2$ \\
\hline 000217 & $\begin{array}{l}\text { NADH-ubiquinone oxidoreductase } 23 \mathrm{kDa} \text { subunit, } \\
\text { mitochondrial precursor }\end{array}$ & $20290 / 5.1$ & 20291 & PMFMS/MS & $0.016 \pm 0.004$ & $0.15 \pm 0.04$ & $9.0 \pm 0.2$ \\
\hline P19012 & Keratin, type I cytoskeletal 15 (Cytokeratin 15) & $49168 / 4.7$ & 49158 & MS/MSPMF & $0.04 \pm 0.01$ & $0.37 \pm 0.16$ & $8 \pm 1$ \\
\hline 008431 & Lactadherin precursor (Milk fat globule-EGF factor 8) & $43123 / 8.5$ & 43088 & PMF & $0.05 \pm 0.02$ & $0.37 \pm 0.07$ & \\
\hline P11142 & Heat shock cognate $71 \mathrm{kDa}$ protein & $70899 / 5.4$ & 70891 & MS/MSPMF & $0.07 \pm 0.01$ & $0.53 \pm 0.15$ & $7 \pm 1$ \\
\hline P04792 & HSP27(SRP 27) (Estrogen regulated protein 24 kDa protein) & $22783 / 6.0$ & 22813 & PMF & $0.017 \pm 0.006$ & $0.98 \pm 0.02$ & $6 \pm 2$ \\
\hline P48643 & $\begin{array}{l}\text { T-complex protein 1, epsilon subunit (TCP-1-epsilon) } \\
\text { (CCT-epsilon) }\end{array}$ & $59672 / 5.5$ & 59643 & PMF & $0.9 \pm 0.2$ & $5 \pm 1$ & $5.6 \pm 0.1$ \\
\hline P35527 & Keratin, type I cytoskeletal 9 (Cytokeratin 9) (K9) (CK 9) & $61988 / 5.1$ & 61988 & MS/MSPMF & $0.016 \pm 0.004$ & $0.08 \pm 0.02$ & $5.4 \pm 0.4$ \\
\hline P10644 & cAMP-dependent protein kinase type i-alpha regulatory chain & $42982 / 5.3$ & 42983 & PMF & $0.019 / 0.024$ & $0.11 / 0.08$ & 5 \\
\hline P10159 & Eukaryotic translation initiation factor 5A (elF-5A) (eIF-4D) & $16832 / 5.1$ & 16842 & PMF & $0.22 \pm 0.05$ & $0.8 \pm 0.2$ & $4 \pm 2$ \\
\hline P10809 & $60 \mathrm{kDa}$ heat shock protein, m.p. (HSP-60) & $57963 / 5.2$ & 57966 & MS/MSPMF & $4.8 \pm 1.1$ & $18.8 \pm 1.6$ & $4 \pm 1$ \\
\hline P22626 & Heterogeneous nuclear ribonucleoprotein A2/B1 & $37430 / 9.0$ & 37431 & MS/MSPMF & $0.017 / 0.023$ & $0.09 / 0.06$ & 4 \\
\hline 014810 & Complexin 1 (Synaphin 2) & $15030 / 4.9$ & 15023 & PMF & $0.9 \pm 0.3$ & $2.8 \pm 0.4$ & $4 \pm 1$ \\
\hline P08670 & Vimentin & $53686 / 5.1$ & 53649 & MS/MSPMF & $1.4 \pm 0.2$ & $5 \pm 1$ & $3.6 \pm 0.2$ \\
\hline P04899 & Guanine nucleotide-binding protein $\mathrm{G}(\mathrm{i})$, alpha-2 subunit & $40451 / 5.3$ & 40449 & PMF & $0.015 \pm 0.002$ & $0.05 \pm 0.01$ & $3 \pm 1$ \\
\hline Q9UJC5 & SH3 domain-binding glutamic acid-rich-like protein 2 & $12326 / 6.3$ & 12351 & PMF & $0.015 \pm 0.003$ & $0.049 \pm 0.005$ & $3 \pm 1$ \\
\hline P05783 & Keratin, type I cytoskeletal 18 (Cytokeratin 18) (CK 18) & $48058 / 5.3$ & 48062 & MS/MSPMF & $1.4 \pm 0.3$ & $4.5 \pm 0.5$ & $3.2 \pm 0.4$ \\
\hline Q8N257 & Histone $\mathrm{H} 2 \mathrm{~B}$ type 12 & $13777 / 10$ & 13786 & MS/MSPMF & $0.35 \pm 0.02$ & $1.1 \pm 0.4$ & $3 \pm 1$ \\
\hline P22087 & Fibrillarin (34 kDa nucleolar scleroderma antigen) & $33784 / 10.2$ & 33791 & PMF & $0.194 \pm 0.006$ & $0.54 \pm 0.15$ & $3 \pm 1$ \\
\hline P08574 & $\begin{array}{l}\text { Cytochrome } \mathrm{c} 1 \text {, heme protein, mitochondrial precursor } \\
\text { (Cytochrome c-1) }\end{array}$ & $27352 / 6.5$ & 27360 & MS/MSPMF & $0.09 \pm 0.01$ & $0.24 \pm 0.01$ & $2.6 \pm 0.1$ \\
\hline P05787 & Keratin, type II cytoskeletal 8 (Cytokeratin 8) & $53675 / 5.5$ & 53670 & MS/MSPMF & $0.25 \pm 0.05$ & $0.59 \pm 0.03$ & $2.4 \pm 0.4$ \\
\hline P20827 & Ephrin-A1 precursor & $23771 / 6.5$ & 23644 & PMF & $0.025 \pm 0.009$ & $0.06 \pm 0.02$ & $2.3 \pm 0.5$ \\
\hline P46108 & Proto-oncogene C-crk (P38) (Adapter molecule crk) & $33872 / 5.5$ & 33847 & PMF & $0.07 \pm 0.02$ & $0.15 \pm 0.04$ & $2.3 \pm 0.3$ \\
\hline P13797 & T-plastin & $70436 / 5.5$ & 70365 & PMF & $0.013 \pm 0.003$ & $0.03 \pm 0.006$ & $2.3 \pm 0.1$ \\
\hline P08758 & Annexin A5 (Annexin V) & $35937 / 4.9$ & 35921 & PMF & $0.37 \pm 0.04$ & $0.78 \pm 0.20$ & $2.1 \pm 0.3$ \\
\hline P31943 & heterogeneous nuclear ribonucleoprotein $\mathrm{H}$ & $49230 / 5.9$ & 49215 & MS/MSPMF & $0.87 \pm 0.22$ & $1.7 \pm 0.3$ & $2 \pm 0.2$ \\
\hline P28676 & Grancalcin & $24010 / 5.0$ & 24014 & PMF & $0.011 \pm 0.004$ & $0.021 \pm 0.004$ & $2 \pm 0.3$ \\
\hline 015714 & Regulatory protein TSC-22 (TGFB stimulated clone 22 homolog) & $15680 / 5.1$ & 15683 & PMF & $0.009 / 0.01$ & $0.016 / 0.020$ & 1.9 \\
\hline 09UK45 & U6 snRNA-associated- Sm-like protein LSm7 & $11595 / 5.1$ & 11601 & PMF & $0.038 \pm 0.002$ & $0.07 \pm 0.02$ & $1.8 \pm 0.5$ \\
\hline P20674 & CYTOCHROME C OXIDASE POLYPEPTIDE VA, m.p. & $12513 / 4.9$ & 12509 & MS/MSPMF & $1.36 \pm 0.37$ & $2.26 \pm 0.35$ & $1.7 \pm 0.2$ \\
\hline 008116 & Regulator of G-protein signaling 1 (RGS1) & $22475 / 8.3$ & 22489 & PMF & $0.056 / 0.064$ & $0.11 / 0.08$ & 1.6 \\
\hline P17980 & $26 \mathrm{~S}$ protease regulatory subunit $6 \mathrm{~A}(\mathrm{TBP}-1)$ & $49204 / 5.1$ & 49208 & PMF & $0.66 \pm 0.13$ & $1.06 \pm 0.38$ & $1.6 \pm 0.4$ \\
\hline P02304 & Histone $\mathrm{H} 4$ & $11367 / 11$ & 11305 & PMF & $0.19 / 0.16$ & $0.3 / 0.2$ & 1.5 \\
\hline P06576 & ATP synthase beta chain, mitochondrial precursor & $51769 / 5.0$ & 51771 & MS/MSPMF & $1.04 \pm 0.33$ & $1.42 \pm 0.28$ & $1.4 \pm 0.2$ \\
\hline 043399 & Tumor protein D54 (hD54) (D52-like 2) & $22238 / 5.3$ & 22208 & MS/MSPMF & $0 . .028 \pm 0.008$ & $0.035 \pm 0.007$ & $1.3 \pm 0.2$ \\
\hline P02570 & Actin, cytoplasmic 1 (Beta-actin) & $41737 / 5.3$ & 41720 & MS/MSPMF & $2.2 \pm 0.3$ & $2.87 \pm 0.58$ & $1.3 \pm 0.1$ \\
\hline P02571 & Actin, cytoplasmic 2 (Gamma-actin) & $41793 / 5.3$ & 41766 & MS/MSPMF & $2 \pm 0.3$ & $2.65 \pm 0.54$ & $1.2 \pm 0.1$ \\
\hline
\end{tabular}


Table 3. Continued

\begin{tabular}{|c|c|c|c|c|c|c|c|}
\hline \multirow[t]{2}{*}{ Acc \# } & \multirow[t]{2}{*}{ Protein ID } & \multirow{2}{*}{$\begin{array}{l}\text { Theo } \\
\text { MW/p } /\end{array}$} & \multirow{2}{*}{$\begin{array}{l}\text { Exp } \\
\text { MW }\end{array}$} & \multirow{2}{*}{$\frac{\text { Identification }}{\text { Method }}$} & \multirow{2}{*}{$\frac{\text { Expression }}{\ln A T 1^{d)}}$} & \multirow{2}{*}{$\frac{\text { Expression }}{\text { In AT1E2 }^{\mathrm{e})}}$} & \multirow[t]{2}{*}{ Change $^{c)}$} \\
\hline & & & & & & & \\
\hline P30101 & Protein disulfide isomerase $\mathrm{A} 3$ precursor (ERp60) & $54265 / 5.6$ & 54264 & MS/MSPMF & $0.27 \pm 0.06$ & $0.33 \pm 0.10$ & $1.2 \pm 0.1$ \\
\hline P05387 & $60 S$ acidic ribosomal protein $\mathrm{P} 2$ & $11665 / 4.4$ & 11648 & PMF & $0.06 \pm 0.03$ & $0.07 \pm 0.01$ & $1.2 \pm 0.3$ \\
\hline 075489 & NADH-ubiquinone oxidoreductase 30 kDa subunit, m.p. & $30242 / 7.0$ & 30195 & PMF & $0.20 \pm 0.06$ & $0.23 \pm 0.03$ & $1.2 \pm 0.2$ \\
\hline P07355 & Annexin A2 (Annexin II) (Lipocortin II) & $38604 / 7.6$ & 38600 & MS/MSPMF & $21.4 \pm 1.9$ & $25.8 \pm 3.7$ & $1.2 \pm 0.1$ \\
\hline P02568 & Actin, alpha skeletal muscle (Alpha-actin 1) & $42051 / 5.2$ & 42151 & MS/MSPMF & $0.04 / 0.03$ & $0.03 / 0.04$ & 1.2 \\
\hline 075306 & NADH-ubiquinol oxidoreductase 49 kDa subunit, m.p. & $52546 / 7.2$ & 52624 & PMF & $0.034 \pm 0.015$ & $0.04 \pm 0.01$ & $1.2 \pm 0.2$ \\
\hline Q9UJT0 & Tublin eplison chain (Epsilon tublin) & $52932 / 6.2$ & 52933 & PMF & $1.18 \pm 0.31$ & $1.33 \pm 0.59$ & $1.1 \pm 0.2$ \\
\hline 075556 & Mammaglobin B precursor (Mammaglobin 2) & $10884 / 5.5$ & 10952 & MS/MSPMF & $0.034 \pm 0.018$ & $0.033 \pm 0.008$ & 1.1 \\
\hline 075947 & ATP synthase D chain, mitochondrial (My032 protein) & $18491 / 5.2$ & 18467 & MS/MSPMF & $0.13 \pm 0.05$ & $0.10 \pm 0.03$ & $-1.3 \pm 0.1$ \\
\hline 000300 & $\begin{array}{l}\text { Tumor necrosis factor receptor superfamily member 11B } \\
\text { precursor }\end{array}$ & $46041 / 8.7$ & 45967 & PMF & $0.14 \pm 0.04$ & $0.09 \pm 0.01$ & $-1.5 \pm 0.3$ \\
\hline P35080 & Profilin II & $15046 / 6.5$ & 15010 & PMF & $0.14 \pm 0.06$ & $0.08 \pm 0.02$ & $-1.6 \pm 0.3$ \\
\hline P24539 & ATP synthase B chain, m.p. & $24625 / 9.1$ & 24632 & PMF & $025 \pm 0.07$ & $0.13 \pm 0.02$ & $-1.9 \pm 0.2$ \\
\hline P84103 & Splicing factor, arginine/serine-rich 3 & 19330/11.6 & 19268 & MS/MSPMF & $0.063 / 0.097$ & $0.02 / 0.03$ & -3 \\
\hline 075531 & Barrier to antointegration factor & $10059 / 5.8$ & 10054 & PMF & $0.14 \pm 0.06$ & $0.046 \pm 0.012$ & $-3.0 \pm 0.4$ \\
\hline $09 Y 265$ & RuvB-like 1 (NMP 238) & $50228 / 6.0$ & 50222 & MS/MSPMF & $0.44 \pm 0.15$ & $0.14 \pm 0.04$ & $-3.1 \pm 0.3$ \\
\hline P07951 & Tropomyosin beta chain (Tropomyosin 2) & $32851 / 4.7$ & 32861 & PMF & $0.021 \pm 0.004$ & $0.006 \pm 0.002$ & -3.4 \\
\hline P42771 & Cyclin-dependent kinase 4 inhibitor A (CDK4I) (p16-INK4) & $16533 / 5.5$ & 16530 & PMF & $1.31 \pm 0.31$ & $0.33 \pm 0.06$ & $-4.0 \pm 0.3$ \\
\hline P31947 & 14-3-3 sigma & $27774 / 4.7$ & 27785 & MS/MSPMF & $0.054 \pm 0.017$ & $0.011 \pm 0.002$ & $-5 \pm 1$ \\
\hline Q9NPJ6 & $\begin{array}{l}\text { Vitamin D3 receptor-interacting protein complex } 36 \mathrm{kDa} \\
\text { component (DRIP36) }\end{array}$ & $29746 / 5.0$ & 29747 & PMF & 2. \pm 0.2 & $0.4 \pm 0.1$ & $-6 \pm 1$ \\
\hline P15531 & Nucleoside diphosphate kinase A (NDK A) & $17149 / 5.8$ & 17212 & PMF & $0.75 \pm 0.13$ & $0.14 \pm 0.04$ & $-6 \pm 1$ \\
\hline P25705 & ATP synthase alpha chain, mitochondrial precursor & $55209 / 8.3$ & 55206 & MS/MSPMF & $6.18 \pm 0.75$ & $0.32 \pm 0.09$ & $-20 \pm 3$ \\
\hline P08559 & Pyruvate dehudrogenase E1 component alpha subunit, m.p. & $43296 / 8.3$ & 43217 & MS/MSPMF & $1.7 \pm 0.2$ & $0.06 \pm 0.01$ & $-28 \pm 2$ \\
\hline
\end{tabular}

c) Protein quantity changes of MCF10AT1E2 versus MCF10AT1 between -4 to +4 is in grey.

Standard deviation obtained from 3 replicate experiments is indicated. The protein quantity change without STD is the average of two replicate experiments.

d), e) The mean value of protein expression and the standard deviation obtained from 3 replicate experiments are indicated. For the proteins in which only two values are available, both values are reported.

Table 4. Selected proteins identified by MALDI-MS, not detected in ESI-MS experiment

\begin{tabular}{|c|c|c|c|}
\hline \multirow[t]{2}{*}{ Acc \# } & \multirow[t]{2}{*}{ Protein ID } & \multirow[t]{2}{*}{ Theo MW/p/ } & \multirow{2}{*}{$\frac{\text { Identification }}{\text { Method }}$} \\
\hline & & & \\
\hline 013541 & Eukaryotic translation initiation factor $4 \mathrm{E}$ binding protein 1 (4E-BP1) & $12580 / 5.3$ & PMF \\
\hline P42772 & Cyclin-dependent kinase 4 inhibitor B (p14-INK4b) (p15-INK4b) & $14722 / 6.1$ & PMF \\
\hline 099653 & Calcium-binding protein p22 (Calcium-binding protein CHP) & $22456 / 5.0$ & MS/MSPMF \\
\hline Q9UMX6 & Guanylyl cyclase activating protein 2 (GCAP 2) (Guanylate cyclase activator 1B) & $23478 / 4.7$ & PMF \\
\hline Q9HCN8 & Stromal Cell-derived factor 2-like protein 1 precursor & $23599 / 6.5$ & PMF \\
\hline 016629 & Splicing factor, arginine/serine-rich 7 & $27367 / 12$ & MS/MSPMF \\
\hline P29312 & 14-3-3 protein zeta/delta (Protein kinase $C$ inhibitor protein-1) & $27745 / 4.7$ & PMF \\
\hline P07226 & Tropomyosin alpha 4 chain (Tropomyosin 4) (TM30p1) & $28522 / 4.7$ & PMF \\
\hline P42655 & 14-3-3 protein epsilon (Mitochondrial import stimulation factor $L$ subunit) & $29174 / 4.6$ & PMF \\
\hline 043736 & integral membrane protein $2 \mathrm{~A}$ & $29742 / 5.6$ & PMF \\
\hline P40222 & Hypothetical protein initially thought to be identical with interleukin-14 (IL-14) & $30107 / 6.3$ & PMF \\
\hline P47756 & F-actin capping protein beta subunit (CapZ beta) & $31351 / 5.4$ & MS/MSPMF \\
\hline P30281 & G1/S-specific cyclin D3 & $32520 / 6.7$ & PMF \\
\hline 015181 & Inorganic pyrophosphatase (Pyrophosphate phospho-hydrolase) (PPase) & $32660 / 5.5$ & MS/MSPMF \\
\hline P52907 & F-actin capping protein alpha- 1 subunit (CapZ alpha-1) & $32923 / 5.4$ & MS/MSPMF \\
\hline 001105 & Phosphatase $2 \mathrm{~A}$ inhibitor I2PP2A & $33489 / 4.2$ & MS/MSPMF \\
\hline P06493 & Cell division control protein 2 homolog (p34 protein kinase) & $34096 / 8.4$ & PMF \\
\hline P49888 & Estrogen sulfotransferase (Sulfotransferase, estrogen-preferring) (EST-1) & $35127 / 6.2$ & PMF \\
\hline
\end{tabular}


Table 4. Continued

\begin{tabular}{|c|c|c|c|}
\hline \multirow[t]{2}{*}{ Acc \# } & \multirow[t]{2}{*}{ Protein ID } & \multirow[t]{2}{*}{ Theo MW/p/ } & \multirow{2}{*}{$\frac{\text { Identification }}{\text { Method }}$} \\
\hline & & & \\
\hline 000214 & Galectin-8 (Gal-8) (Prostate carcinoma tumor antigen 1) (PCTA-1) & $35539 / 7.1$ & PMF \\
\hline P30519 & Heme oxygenase 2 (HO-2) & $36033 / 5.3$ & PMF \\
\hline 095755 & Ras-related protein Rab-36 & $36324 / 7.5$ & PMF \\
\hline P04270 & Actin, alpha cardiac & $42019 / 5.2$ & PMF \\
\hline P48667 & Keratin, type II cytoskeletal 6D (Cytokeratin 6D) (CK 6D) (K6D keratin) & $42469 / 5.3$ & MS/MSPMF \\
\hline 016795 & NADH-ubiquinone oxidoreductase 39 kDa subunit, m.p. & $42510 / 9.8$ & PMF \\
\hline P04637 & Cellular tumor antigen p53 (Tumor suppressor p53) & $43654 / 6.3$ & PMF \\
\hline P52597 & Heterogeneous nuclear ribonucleoprotein $\mathrm{F}$, nucleo-like protein & $45541 / 5.4$ & MS/MS,PMF \\
\hline 012849 & G-rich sequence factor-1 (GRSF-1) & $48000 / 5.5$ & PMF \\
\hline 09C075 & Keratin, type I cytoskeletal 23 (Cytokeratin 23) (K23) (CK 23) & $48068 / 6.0$ & MS/MSPMF \\
\hline Q9UKS6 & Protein kinase $C$ and casein kinase substrate in neurons protein 3 & $48487 / 5.8$ & PMF \\
\hline P35900 & Keratin, type I cytoskeletal 20 (Cytokeratin 20) (K20) (CK 20) & $48487 / 5.5$ & PMF \\
\hline 075390 & Citrate synthase, mitochondrial precursor & $51707 / 8.1$ & PMF \\
\hline Q9Y6N5 & Sulfide:quinone oxidoreductase, mitochondrial precursor (CGI-44) & $49961 / 9.2$ & MS/M PMF \\
\hline P61978 & heterogeneous nuclear ribonucleoprotein $\mathrm{K}$ & $50976 / 5.2$ & MS/MSPMF \\
\hline 013451 & FK506-binding protein 5 (Peptidyl-prolyl cis-trans isomerase) (PPlase) & $51213 / 5.7$ & MS/MSPMF \\
\hline P08779 & Keratin, type I cytoskeletal 16 (Cytokeratin 16) (K16) (CK 16) & $51268 / 5.0$ & PMF \\
\hline $\mathrm{P} 02533$ & Keratin, type I cytoskeletal 14 (Cytokeratin 14) (K14) (CK 14) & $51622 / 5.1$ & PMF \\
\hline P45452 & Collagenase 3 precursor (Matrix metalloproteinase-13) (MMP-13) & $53820 / 5.3$ & PMF \\
\hline $09 Y 512$ & Sam 50-like protein CGI-51 & $51963 / 6.4$ & MS/MSPMF \\
\hline P17661 & Desmin & $53536 / 5.2$ & PMF \\
\hline P07237 & Protein disulfide isomerase precursor (PDI) (Prolyl 4-hydroxylase beta subunit) & $57117 / 4.8$ & PMF \\
\hline P06239 & Proto-oncogene tyrosine-protein kinase LCK (P56-LCK) (LSK) & $58001 / 5.2$ & PMF \\
\hline 075363 & Breast carcinoma amplified sequence 1 (Novel amplified in breast cancer 1) & $61719 / 5.0$ & PMF \\
\hline P13647 & Keratin, type II cytoskeletal 5 (Cytokeratin 5) (K5) (CK 5) (58 kDa cytokeratin) & $62462 / 8.1$ & MS/MSPMF \\
\hline 013131 & $5^{\prime}$-AMP-activated protein kinase, catalytic alpha- 1 chain (AMPK alpha- 1 chain) & $62794 / 7.3$ & PMF \\
\hline 014682 & Ectoderm-neural cortex-1 protein (ENC-1) (P53-induced protein 10) & $66130 / 6.4$ & PMF \\
\hline P03372 & Estrogen receptor (ER) (Estradiol receptor) (ER-alpha) & $66216 / 8.3$ & PMF \\
\hline P20700 & Lamin B1 & $66409 / 5.1$ & MS/MSPMF \\
\hline 003252 & Lamin B2 & $67689 / 5.3$ & PMF \\
\hline P35240 & Merlin (Moesin-ezrin-radixin-like protein) (Schwannomin) & $69691 / 6.1$ & PMF \\
\hline 002153 & Guanylate cyclase soluble, beta-1 chain (GCS-beta-1) & $70515 / 5.2$ & PMF \\
\hline 09H4B4 & Cytokine-inducible serine/threonine-protein kinase (FGF-inducible kinase) & $71790 / 9.3$ & PMF \\
\hline 075509 & Tumor necrosis factor receptor superfamily member 21 precursor & $71846 / 8.1$ & PMF \\
\hline P13667 & Protein disulfide isomerase A4 precursor (Protein ERp-72) (ERp72) & $72933 / 5.0$ & PMF \\
\hline P02545 & Lamin A/C (70 kDa lamin) & $74140 / 6.6$ & MS/MSPMF \\
\hline P19338 & Nucleolin (Protein C23) & $76345 / 4.6$ & MS/MSPMF \\
\hline P23246 & Splicing factor, proline-and glutamine-rich & $76149 / 9.4$ & MS/MSPMF \\
\hline Q9UQF2 & C-jun-amino-terminal kinase interacting protein 1 (JNK-interacting protein 1) & $77525 / 4.9$ & MS/MSPMF \\
\hline P57058 & Hormonally upregulated neu tumor-associated kinase & $79686 / 9.2$ & PMF \\
\hline 008493 & cAMP-specific 3',5'-cyclic phosphodiesterase 4C (DPDE1) (PDE21) & $79902 / 5.1$ & PMF \\
\hline P08238 & Heat shock protein HSP 90-beta (HSP 84) (HSP 90) & $83265 / 5.0$ & PMF \\
\hline 075330 & Hyaluronan mediated motility receptor (Intracellular hyaluronic acid binding protein) & $84032 / 5.6$ & PMF \\
\hline $09 Y 2 X 7$ & ARF GTPase-activating protein GIT1 (G protein-coupled receptor kinase-interactor 1) & $84332 / 6.3$ & PMF \\
\hline 016549 & Proprotein convertase subtilisin/kexin type 7 precursor (Proprotein convertase PC7) & $86248 / 5.5$ & MS/MSPMF \\
\hline P42224 & Signal transducer and activator of transcription 1-alpha/beta & $87336 / 5.7$ & PMF \\
\hline Q96CN9 & Golgi coiled coil protein 1 & $87811 / 5.3$ & PMF \\
\hline P22455 & Fibroblast growth factor receptor 4 precursor (FGFR-4) & $87955 / 6.4$ & PMF \\
\hline P17480 & Nucleolar transcription factor 1 (Upstream binding factor 1) (UBF-1) & $89407 / 5.6$ & PMF \\
\hline 08WXW3 & Progesterone-induced blocking factor 1 & $89774 / 5.8$ & PMF \\
\hline 095294 & RasGAP-activating-like protein 1 & $89998 / 6.1$ & PMF \\
\hline 015394 & Neural cell adhesion molecule 2 precursor (N-CAM2) & $92933 / 5.8$ & PMF \\
\hline P34932 & HEAT SHOCK 70 KDA PROTEIN 4 (HEAT SHOCK 70-RELATED PROTEIN APG-2) & $94301 / 5.2$ & PMF \\
\hline P16591 & Proto-oncogene tyrosine-protein kinase FER (p94-FER) (c-FER) & $94625 / 6.7$ & PMF \\
\hline P45974 & Ubiquitin carboxyl-terminal hydrolase 5 (Ubiquitin thiolesterase 5) & $95787 / 4.9$ & PMF \\
\hline 092598 & Heat-shock protein $105 \mathrm{kDa}$ & $96866 / 5.3$ & PMF \\
\hline P16144 & Integrin beta-4 precursor (GP 150) (CD 104 antigen) & $202023 / 5.7$ & MS/MSPMF \\
\hline
\end{tabular}


Table 5. Proteins detected as truncated form by ESI-MS

\begin{tabular}{|c|c|c|c|c|c|}
\hline Acc \# & Protein ID & Theo MW/p/ & Exp MW & Cleaved Form & Cleaved AA \\
\hline P08574 & Cytochrome c1, heme protein, mitochondrial precursor & $35390 / 9.1$ & 27360 & $27352 / 6.5$ & $1 \sim 84$ \\
\hline 095881 & Thioredoxin-like protein p19 precursor & $19206 / 5.2$ & 16435 & $16426 / 5.2$ & $1 \sim 26$ \\
\hline 000217 & $\mathrm{NADH}$-ubiquinone oxidoreductase $23 \mathrm{kDa}$ subunit, mitochondrial precursor & $23705 / 6.0$ & 20291 & $20290 / 5.1$ & $1 \sim 34$ \\
\hline 014763 & Tumor necrosis factor receptor superfamily member 10B precursor & $47851 / 5.4$ & 42161 & $42202 / 5.0$ & $1 \sim 55$ \\
\hline P11021 & 78 kDa glucose-regulated protein precursor & $72334 / 5.1$ & 70507 & $70478 / 5.0$ & $1 \sim 18$ \\
\hline Q9BZD7 & Transmembrane gamma-carboxyglutamic acid protein 3 precursor & $25848 / 5.8$ & 23650 & $23650 / 5.3$ & $1 \sim 19$ \\
\hline P10109 & Adrenodoxin, mitochondrial precursor & $19393 / 5.5$ & 13577 & $13561 / 4.4$ & $1 \sim 60$ \\
\hline P12074 & Cytochrome c oxidase polypeptide Vla-liver, m.p. & $12155 / 9.3$ & 9619 & $9619 / 6.4$ & $1 \sim 24$ \\
\hline P38646 & Stress-70 protein, mitochondrial precursor & $73681 / 5.9$ & 68763 & $68759 / 5.4$ & $1 \sim 46$ \\
\hline Q9UBC7 & Galanin-like peptide precursor & $12545 / 5.9$ & 10128 & $10118 / 6.3$ & $1 \sim 24$ \\
\hline P49411 & Elongation factor Tu, mitochondrial precursor (EF-Tu) (P43) & $49542 / 7.3$ & 45047 & $45045 / 6.3$ & $1 \sim 43$ \\
\hline P10809 & $60 \mathrm{kDa}$ heat shock protein, m.p. (HSP-60) & $61055 / 5.7$ & 57966 & $57963 / 5.2$ & $1 \sim 26$ \\
\hline P20674 & CYTOCHROME C OXIDASE POLYPEPTIDE VA, m.p. & $16774 / 6.3$ & 12509 & $12513 / 4.9$ & $1 \sim 41$ \\
\hline P06576 & ATP synthase beta chain, mitochondrial precursor & $56560 / 5.3$ & 51771 & $51769 / 5.0$ & $1 \sim 47$ \\
\hline P30101 & Protein disulfide isomerase $\mathrm{A} 3$ precursor (ERp60) & $56783 / 6.0$ & 54264 & $54265 / 5.6$ & $1 \sim 24$ \\
\hline P24539 & ATP synthase B chain, m.p. & $28909 / 9.4$ & 24632 & $24625 / 9.1$ & $1 \sim 42$ \\
\hline P25705 & ATP synthase alpha chain, mitochondrial precursor & $59751 / 9.2$ & 55210 & $55209 / 8.3$ & $1 \sim 43$ \\
\hline
\end{tabular}

between the two samples. Annexin A2 is a reported marker protein [22], but its expression level remain unchanged upon estrogen treatment. The SD of the changes is within $20 \%$. Actually, the same SD window can be applied to proteins with low abundance such as NADH-ubiqinol oxidoreductase 49 kDa subunit.

\subsubsection{Proteins with changes in expression}

In Table 3, many proteins have changes greater than twofold. Among them, Hsp60, CK8, CK15, CK7, CK18 are welldocumented marker proteins in breast cancer [23-26]. They are mostly structural proteins that have no relation with signal pathways. Moreover, they are typically expressed at high levels, which is true in MCF10AT1 and MCF10AT1E2. Therefore, these proteins are of limited interest.

In addition to accurate mass and accurate $\mathrm{p} I$, another improvement on the 2-D mass map generated by the CFNPS-RP-HPLC-online-ESI-TOF-MS analysis is quantitation. As described previously, the abundance of a protein is measured by the peak area in the deconvoluted MS spectrum. MS is a mass specific detector that can resolve and quantify multiple proteins in a single detection. Therefore, coeluting proteins, that are difficult to quantify in 2-D gel-based techniques, can be resolved and quantified by the MS-based liquid 2-D protein profiling method. This allows the quantification of low-abundance proteins. To minimize the determination of false changes, all proteins with changes higher than 4 are considered changed. In Table 3, WT1 (Q15007) and thioredoxin (Q99757) are both weakly expressed in MCF10AT1 cells, but their expression is significantly elevated upon estrogen treatment. It is not surprising since WT1 protein (Q15007) is correlated with the proliferation of breast cancer cells and it functions partially as an oncogene by stimulating the expression of c-myc proto-oncogene [27, 28]. It should be pointed out that MCF10AT1E2 cells are premalignant. The expression of WT1 protein after the estrogen treatment could be an upstream event that induces the progression of breast cancer. Thioredoxin (Q99757) is one of the major proteins regulating intracellular redox metabolism and it is activated in response to oxidative stress. Studies have shown that the expression of thioredoxin mRNA can be induced by estrogen [29]. The direct evidence of the increased expression of thioredoxin upon estrogen exposure has never been reported. HSP27 (P04792), also referred to as the estrogen-regulated $24 \mathrm{~K}$ protein, is six times more highly expressed in the estrogen-treated MCF10AT1 cells. Its expression is physiologically related to cell growth and differentiation. Our observation agrees with the suggestion that the differential expression of HSP27 is an important determinant in initiating or promoting a population of human mammary cancers [30].

As shown in Table 3, the expression of stress-70 protein (P38646, GRP75) was elevated ten times upon estrogen treatment. Interestingly, the Western blot analysis of GRP75 protein in total cell lysates of MCF10AT1 and MCF10AT1E2 cells suggests a slight increase (Fig. 7A). However, the analysis of the same protein using Western blot for fractions eluted from the CF column from MCF10AT1 (Fig. 7B) and MCF10AT1E2 (Fig. 7C) cell lysate indicated that approximately eight-fold higher level of GRP75 is detected in estrogen-treated MCF10AT1 cells as compared to the control following fractionation. The results suggest that additional isoforms of GRP75 protein may be present outside the $\mathrm{pH}$ range analyzed. It should be noted that a significant portion of GRP75 in MCF10AT1E2 cells appears as a doublet band (compare lanes 2 and 3 in Fig. 7B and C) indicating estrogen-induced PTM, possibly phosphorylation since it predominantly elutes 


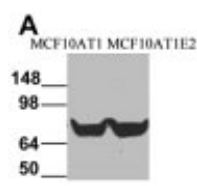

B

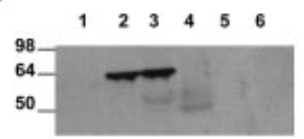

C

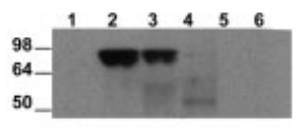

Figure 7. Western blot analysis of Grp75 protein in total cell lysates of MCF10AT1 (untreated) and MCF10AT1E2 (estrogentreated) cells (panel A), and of fractions eluted from CF column from untreated (panel B) and estrogen-treated (panel C) MCF10AT1 cells. Lane 1, pH 5.0-4.8; lane 2, 5.0-5.2; lane 3, 5.25.4; lane 4, 5.4-5.6; lane 5, 5.6-5.8; lane 6, 5.8-6.0.

at lower $\mathrm{pH}(5.2-5.0)$, and a peak at $68840 \mathrm{Da}, \sim 80 \mathrm{Da}$ higher than the theoretical MW of $68763 \mathrm{Da}$, was observed in the estrogen-treated sample. The result revealed the limitation of the traditional 1-D gel separation and supported the advantage of the high-resolution 2-D liquid separation in analysis of complex samples such as whole cell lysate. It should be also noted that GRP75 was shown in 4.8-5.2 fractions in the AT1 map and in 5.0-5.6 in the AT1E2 map as indicated in Fig. 3b. There might be a pH shift due to temperature difference or calibration/electrode difference in separate experiments. It is thus possible that individual isoforms may be identified in adjacent $\mathrm{pH}$ fractions in separate experiments.

Some proteins can only be detected in one cell line by ESI-TOF-MS. Those detected only in MCF10AT1E2 cells are shown in Table 1, and those detected only in MCF10AT1 are shown in Table 2. In order to estimate the changes of these proteins, the normalized peak area of each protein is divided by that of the WT1 protein (Q15007), which is the lowest abundant protein detected using the liquid 2-D protein profiling method. As shown in Table 1, GRB2-related adaptor protein 2 (O75791), trefoil factor 1 (P04155), LIM domain kinase 1 (P53667), apoptosis regulator Bcl-W (Q92843), G1S-specific cyclin D1 (P24385), and c-myc (P01106) can only be observed in MCF10AT1E2 cells, which indicates the upregulation of these proteins after estrogen treatement. GRB2-related adaptor protein 2 couples tyrosine kinase to the ras signaling pathway [31]. Since the MCF10AT1 cell line is derived from MCF10A cells by c-Ha-ras gene transfection, the observation of GRB2-related adaptor protein indicates the activation of the ras signaling pathway. In addition to the GRB2-related adaptor protein, other proteins observed and involved in the ras signaling pathway include mortalin (P38646, Table 3) [32] and galectin 1 (P09382, Table 3) which have been elevated by 17 - and 11-fold, respectively. The increase of galectin 1 mediates ras membrane anchorage and cell transformation [33], and enhances ras signal transduction response to EGF [34]. LIM domain kinase 1 (P53667) is a critical regulator of actin dynamics. It plays a regulatory role in tumor cell invasion. The significant elevation of this protein in MCF10AT1E2 is unexpected since MCF10AT1E2 is still premalignant and noninvasive. Apoptosis regulator Bcl-W (Q92843) promotes cell survival. Increased expression of this protein suggests the decrease of apoptotic signaling. G1-S-specific cyclin D1 (P24385) and c-myc (P01106) are two other proteins which are up-regulated and play an important role in signal pathways. They were identified in both cell lines by MALDI-MS, but their intact form in MCF10AT1 is below the detection limit of the method. Cyclin D1 is essential for the control of the cell cycle at the G1/S transition. The results agree with the positive correlation of the mRNA study of cycline D1 with the ER [35]. On the other hand, c-myc participates in the regulation of gene transcription. C-myc expression may be an important step in the estrogen-induced proliferation of human breast cancer cells [36].

Other proteins were down-regulated upon estrogen treatment. Among them, 14-3-3 protein tau (P27348, Table 2) can only be detected in MCF10AT1, while another protein in the 14-3-3 family, 14-3-3 protein sigma (P31947), is downregulated by five-fold after estrogen treatment. The 14-3-3 family is a highly conserved family of proteins that play a role in the regulation of signal transduction pathways implicated in the control of cell proliferation, differentiation, and survival. Other important down-regulated proteins include BCL2 protein (Q12983, Table 2), growth arrest and DNAdamage-inducible protein GADD45 gamma (O95257, Table 2), tropomyosin 1 alpha chain (P09493, Table 2), and tropomyosin beta chain (P07951, Table 3).

\subsubsection{Proteins with no quantitative information}

Proteins remain in solution during the $\mathrm{CF}$ and the RP separation. This feature significantly improves the recovery of tryptic peptides, which allows $\sim 300$ proteins identified for MCF10AT1 and MCF10AT1E2 in pH 4.6-6.0. In this study, many bands corresponding to proteins identified by MALDITOF-MS or MALDI-TOF/TOF-MS analysis are missed on the 2-D mass map. Selected proteins of interest are summarized on Table 4. Around 50\% of these proteins have theoretical $M_{\mathrm{r}}$ greater than $60 \mathrm{~K}$, where the performance of our current ESITOF-MS instrument has limited sensitivity. Some modifications, such as phosphorylation and glycosylation, will decrease the ionization efficiency of proteins. Therefore, heavily modified proteins very likely remain undetected upon ESI-TOF-MS analysis. As a result, the proteins in Table 4 are not quantified although there are some interesting and important proteins such as G1/S-specific cyclin D3 (P30281), EST-1 (P49888), ras-related protein Rab-36 (O95755), cellular tumor antigen p53 (P04637), breast carcinoma amplified sequence 1 (O75363), and ER (P03372).

\section{Concluding remarks}

In this study, a protein profiling method based on CF-NPSRP-HPLC-online-ESI-TOF-MS analysis was developed. 2-D mass maps in the $\mathrm{pH}$ range 4.6-6.0 were generated with good correlation to theoretical values for intact proteins. The application of the method to MCF10AT1 and the estrogen- 
treated MCF10AT1E2 enables the quantification of 120 proteins in mass range $5-75 \mathrm{kDa}$, where $\sim 40$ proteins were found to be up-regulated ( $>$ four-fold) upon estrogen treatment while 17 proteins were down-regulated ( $>$ four-fold). The remaining proteins were found unchanged. There are some over-expressed proteins which might be essential in the estrogen regulation mechanism such as WT-1 protein, thioredoxin, and Hsp27. The up-regulated proteins include G1-S-specific cyclin and c-myc, which play an important role in signal pathways as well as apoptosis regulator Bcl-W and LIMK which have characteristics consistent with the development of a malignant phenotype. In addition, some altered proteins have a role in the ras pathway such as GRB2-related adaptor protein, Mortalin. There are also some interesting proteins found to be down-regulated including 14-3-3 sigma and tropomyosin 1 alpha chain. Further studies on these proteins will reveal the mechanism of breast cancer progression and the effect of estrogen. Our studies suggest the diverse signal network and cell regulatory pathways through which E2 operates to alter the proliferation and phenotype of high-risk premalignant breast cells.

We gratefully acknowledge support of this work by the National Cancer Institute under grants R21CA83808 (DML, FRM), R01CA90503 (FRM, DML), as well as the National Institutes of Health under RO1GM49500 (DML). We also acknowledge the National Science Foundation under grant DBI 99874 for funding of the MALDI-TOF-MS instrument used in this work.

\section{References}

[1] Polyak, K., Biochim. Biophys. Acta 2001, 1552, 1-13.

[2] American Cancer Society, Cancer Facts and Figures 2004, http://www.cancer.org/downloads/stt/caff_finalpwsecured.pdf.

[3] Russo, I. H., Russo, J., J. Mammary Gland Biol. Neoplasia 1998, 3, 49-61.

[4] Anderson, E., Clarke, R. B., Howell, A., J. Mammary Gland Biol. Neoplasia 1998, 3, 23-35.

[5] Hondermarck, H., Dolle, L., El Yazidi-Belkoura, I., VercoutterEdouart, A. S. et al., J. Mammary Gland Biol. Neoplasia 2002, 7, 395-405.

[6] Souchelnytskyi, S., J. Mammary Gland Biol. Neoplasia 2002, 7, 359-371.

[7] Anderson, L., Seilhamer, J., Electrophoresis 1997, 18, 533537.

[8] Aebersold, R., Mann, M., Nature 2003, 422, 198-207.

[9] Hondermarck, H., Vercoutter-Edouart, A. S., Revillion, F., Lemoine, J. et al., Proteomics 2001, 1, 1216-1232.

[10] Osborne, C. K., Hobbs, K., Clark, G. M., Cancer Res. 1985, 45, 584-590.
[11] Soule, H. D., Vazguez, J., Long, A., Albert, S., Brennan, M., J. Natl. Cancer Inst. 1973, 51, 1409-1416.

[12] Lee, G. S., Ryu, K. S., Rha, J. G., Kim, S. P. et al., J. Obstet. Gynaecol. Res. 2002, 28, 141-148.

[13] Lubman, D. M., Kachman, M. T., Wang, H., Gong, S. et al., J. Chromatogr. B Analyt. Technol. Biomed. Life Sci. 2002, 782, 183-196.

[14] Chong, B. E., Hamler, R. L., Lubman, D. M., Ethier, S. P. et al., Anal. Chem. 2001, 73, 1219-1227.

[15] Miller, F. R., J. Mammary Gland Biol. Neoplasia 2000, 5, 379391.

[16] Dawson, P. J., Wolman, S. R., Tait, L., Heppner, G. H., Miller, F. R., Am. J. Pathol. 1996, 148, 313-319.

[17] Bradford, M. M., Anal. Biochem. 1976, 72, 248-254.

[18] Shekhar, M. P., Nangia-Makker, P., Wolman, S. R., Tait, L. et al., Am. J. Pathol. 1998, 152, 1129-1132.

[19] Shekhar, P. V., Chen, M. L., Werdell, J., Heppner, G. H. et al., Int. J. Oncol. 1998, 13, 907-915.

[20] Zhu, K., Miller, F. R., Barder, T. J., Lubman, D. M., J. Mass Spectrom. 2004, 39, 770-780.

[21] Zhu, K., Zhao, J., Lubman, D. M., Miller, F. R., Barder, T. J., Anal. Chem. 2005, 77, 2745-2755.

[22] Hamler, R. L., Zhu, K., Buchanan, N. S., Kreunin, P. et al., Proteomics 2004, 4, 562-577.

[23] Trask, D. K., Band, V., Zajchowski, D. A., Yaswen, P. et al., Proc. Natl. Acad. Sci. USA 1990, 87, 2319-2323.

[24] Sarto, C., Binz, P. A., Mocarelli, P., Electrophoresis 2000, 21, 1218-1226.

[25] Cappello, F., Bellafiore, M., Palma, A., David, S. et al., Eur. J. Histochem. 2003, 47, 105-110.

[26] Franzen, B., Linder, S., Alaiya, A. A., Eriksson, E. et al., Br. J. Cancer 1996, 74, 1632-1638.

[27] Zapata-Benavides, P., Tuna, M., Lopez-Berestein, G., Tari, A. M., Biochem. Biophys. Res. Commun. 2002, 295, 784-790.

[28] Han, Y., San-Marina, S., Liu, J., Minden, M. D., Oncogene 2004, 23, 6933-6941.

[29] Maruyama, T., Sachi, Y., Furuke, K., Kitaoka, Y. et al., J. Endocrinol. 1999, 140, 365-372.

[30] O'Neill, P. A., Shaaban, A. M., West, C. R., Dodson, A. et al., Br. J. Cancer 2004, 90, 182-188.

[31] Feng, G. S., Ouyang, Y. B., Hu, D. P., Shi, Z. Q. et al., J. Biol. Chem. 1996, 271, 12129-12132.

[32] Wadhwa, R., Yaguchi, T., Hasan, M. K., Taira, K., Kaul, S. C., Biochem. Biophys. Res. Commun. 2003, 302, 735-742.

[33] Paz, A., Haklai, R., Elad-Sfadia, G., Ballan, E., Kloog, Y., Oncogene 2001, 20, 7486-7493.

[34] Elad-Sfadia, G., Haklai, R., Ballan, E., Gabius, H. J., Kloog, Y., J. Biol. Chem. 2002, 277, 37169-37175.

[35] Hui, R., Cornish, A. L., McClelland, R. A., Robertson, J. F. et al., Clin. Cancer Res. 1996, 2, 923-928.

[36] Dubik, D., Dembinski, T. C., Shiu, R. P., Cancer Res. 1987, 47, 6517-6521. 